\title{
Ontogenetic scaling patterns and functional anatomy of the pelvic limb musculature in emus (Dromaius novaehollandiae)
}

Luis P Lamas, Russell P Main, John R. Hutchinson

Emus (Dromaius novaehollandiae) are exclusively terrestrial, bipedal and cursorial ratites with some similar biomechanical characteristics to humans. Their growth rates are impressive as their body mass increases eighty-fold from hatching to adulthood whilst maintaining the same mode of locomotion throughout life. These ontogenetic characteristics stimulate biomechanical questions about the strategies that allow emus to cope with their rapid growth and locomotion, which can be partly addressed via scaling (allometric) analysis of morphology. In this study we have collected pelvic limb anatomical data (muscle architecture, tendon length, tendon mass and bone lengths) and calculated muscle physiological cross sectional area (PCSA) and average tendon cross sectional area from emus across three ontogenetic stages ( $n=17$, body masses from 3.6 to $42 \mathrm{~kg}$ ). The data were analysed by reduced major axis regression to determine how these biomechanically relevant aspects of morphology scaled with body mass. Muscle mass and PCSA showed a marked trend towards positive allometry (26 and 27 out of 34 muscles respectively) and fascicle length showed a more mixed scaling pattern. The long tendons of the main digital flexors scaled with positive allometry for all characteristics whilst other tendons demonstrated a less clear scaling pattern. Finally, the two longer bones of the limb (tibiotarsus and tarsometatarsus) also exhibited positive allometry for length and the two others (femur and first phalanx of digit III) had trends towards isometry. These results indicate that emus experience a relative increase in their muscle force-generating capacities, as well as potentially increasing the force-sustaining capacities of their tendons, as they grow. Furthermore, we have clarified anatomical descriptions and provided illustrations of the pelvic limb muscle-tendon units in emus. 


\title{
Ontogenetic scaling patterns and functional anatomy of the pelvic limb musculature in emus (Dromaius novaehollandiae)
}

5

6

7

8

9

\author{
Luis P. Lamas ${ }^{1 *}$, Russell P. Main², John R. Hutchinson ${ }^{1}$
}

1. Structure and Motion Laboratory, Department of Comparative Biomedical Sciences, The Royal Veterinary College, Hawkshead Lane, Hatfield, AL9 7TA, United Kingdom.

2. Department of Basic Medical Sciences, College of Veterinary Medicine, Purdue University, 625 Harrison Street, West Lafayette, IN 47907, USA.

*L.P.Lamas is the Corresponding Author (Ilamas@rvc.ac.uk)

\section{Introduction}

Scaling studies (relating animal body mass to other biological parameters) have broadly elucidated locomotor adaptations across a wide range of body sizes. These studies have also described important size-related biomechanical (Alexander et al. 1979; Bertram \& Biewener 1990; Biewener 1982; Gatesy \& Biewener 1991; LaBarbera 1989; Maloiy et al. 1979; McMahon 1975) and metabolic (Gillooly et al. 2001; Hemmingsen 1960; Hokkanen 1986; Kleiber 1932; Schmidt-Nielsen 1984; Taylor et al. 1981) constraints across species. Intraspecific scaling studies are less common (Allen et al. 2010,2014; Carrier \& Leon 1990; Carrier 1983; Dial \& Jackson 2011; Main \& Biewener 2007; Miller et al. 2008; Picasso 2012a; Smith \& Wilson 2013; Young 2009, Picasso 2014) These ontogenetic approaches yield valuable insights into musculoskeletal adaptations to growth and potentially to identify sizerelated constraints on mechanical function within a species. Furthermore, studies of species where the mode of locomotion and basic anatomy remains similar during development contribute to the understanding of strategies and trade-offs that occur during growth. Such information can, for example, be used to comprehend developmental abnormalities and study intervention strategies to manage them.

Ratites are large flightless birds with cursorial morphology (e.g., Smith et al. 2010; Smith \& Wilson 2013) that makes them attractive subjects for studies of terrestrial locomotion and bipedalism (Abourachid, 2000). Certain characteristics make emus (Dromaius novaehollandiae) particularly useful: they have some anatomical and functional similarities to other bipedal animals, including purportedly humans (Goetz et al. 2008). Compared to ostriches, they are generally easier to handle and train in experimental settings due to their smaller size and calmer temperament. Finally, their growth rate is impressive, as they multiply their body weight $\sim 80$ times in the first 18 months of life (Minnaar \& Minnaar 1998) whilst maintaining the same cursorial mode of locomotion. Despite this interest there are still some discrepancies in published anatomical descriptions and depictions of the pelvic limb musculature of emus (Haughton 1867; Patak \& Baldwin 1998; Vanden Berge \& Zweers 1993), and clear visual anatomical aids are lacking in the literature.

Some of the biomechanical changes in the hindlimb occurring during the growth in emus have been described. Main and Biewener (2007) measured the skeletal strain patterns on the surfaces of the femur and the tibiotarsus (TBT) in running emus, demonstrating a significant increase in the magnitude of cranial and caudal femoral 
52

53

54

55

56

57

58

59

60

61

62

63

64

65

66

67

68

69

70

71

72

73

74

75

76

77

78

79

80

81

82

83

84

85

86

87

88

89

90

91

92

93

and caudal tibiotarsal strains during ontogeny, despite the enlargement and strengthening of those bones via positive allometric scaling of the second moment of area. Muscles have been shown to influence the strain patterns of bones (Yoshikawa et al. 1994), and although other factors are likely to be involved in the changes in peak bone strains reported across ontogeny (Main \& Biewener 2007), allometric scaling of the musculature could also play a role in these differences in bone tissue loading. The strains induced by muscle contraction will be proportional to the muscle forces acting on the bone; therefore by estimating muscle forces (e.g., maximal force capacity based upon anatomy), associations between these two findings would be possible.

In order to build on already available biomechanical data for emus (Goetz et al. 2008; Main \& Biewener 2007), we aim here to quantify the ontogenetic scaling patterns of four pelvic limb bones, pelvic limb muscles and their tendons and in the process describe and compare the functional and descriptive anatomy of the pelvic limb musculature of emus. We use regression analysis to determine the relationship of muscle architectural properties with body mass in an ontogenetic series of emus and then examine the implications of these findings for the locomotor ontogeny of emus, other ratites as well as extinct theropod dinosaurs.

\section{Materials and methods}

Animal subjects and care: UK group

We dissected 17 emus for this study, obtained from our ongoing research examining emu ontogenetic biomechanics (conducted with ethical approval under a UK Home Office license). The emus were divided in three groups of animals according to their age: Group 1: Five individuals at 4-6 weeks old; Group 2: Six 24-28 weeks (6 months) old individuals; and Group 3: Six 64-68 weeks (16 months) old individuals. All birds had been used as experimental animals and kept in a small pen (7x7m) for the first six weeks of life, after which they were moved to an outdoor larger enclosure with grass footing $(40 \mathrm{~m} \times 15 \mathrm{~m})$ until they were six months old; after this they were moved to a large (1.6 hectares) grass field (maximal animal density at one time was 8 birds/ha). The birds were all born in three consecutive yearly breeding seasons. Only the birds in Group 3 were from the same breeding season but not necessarily the same progenitors; birds from the other two Groups were from two different seasons.

All animals were hatched at a commercial breeding farm in the UK and raised from four weeks of age at the Royal Veterinary College. They were fed a commercial ostrich pelleted diet supplemented with grass and from six weeks of age were kept with free access to commercial food and grass. At 24 weeks, their diet changed from an ostrich grower diet to adult ostrich pelleted food (Dodson and Horrel Ltd., Kettering, Northamptonshire, UK). There were no restrictions or enforcements on the animals' regular exercise regime and all animals were allowed the same area and conditions to exercise during their development. All animals were euthanized after other experimental procedures were completed, by lethal intravenous injection of a barbiturate following induction of deep terminal general anaesthesia by intramuscular injection of ketamine and xylazine. Carcasses were kept frozen in a $-20^{\circ} \mathrm{C}$ freezer for up to 2 years before dissection. Thawing was allowed at variable ambient temperatures and for variable amounts of time depending on the size of the animal, and dissection started no longer than 4 days after removal from the freezer. All dissections were performed within a six week period and led by the same individual (L.P.L.). 
101

102

103

122

123

124

125

126

127

128

129

130

131

132

133

134

135

136

137

138

139

140

USA group of emus

Unpublished raw data of muscle masses from a different group of 29 emus ( 0.74 to $51.7 \mathrm{~kg}$ body mass) used for similar purposes as those described for the UK group were also included in this study. This group was bred and reared in the USA (Concord Field Station, Harvard University) under the care of another investigator (R.P.M.) who led all dissections for this group. The size and age composition for this group was more heterogeneous, and only body masses and muscle masses were available for analysis. Because the purpose of the dissections in the group was not a systematic ontogenetic musculoskeletal scaling study, the number of muscles dissected per animal varied.

\section{Bone measurements}

Maximal interarticular lengths of the femur, tibiotarsus (TBT), tarsometatarsus (TMT) and first phalanx of the middle (third) digit were measured using an ordinary flexible measuring tape $( \pm 1 \mathrm{~mm})$ once they were cleared of all soft tissues.

\section{Myology and muscle architecture}

We identified muscles of emus using four separate literature sources (Haughton 1867; Patak \& Baldwin 1998; Smith et al. 2007; Vanden Berge \& Zweers 1993); when our observations differed from these, we described the anatomical landmarks and attachments in detail according to our observations. General main actions of the muscle were defined based on these publications and confirmed by identifying the muscle attachments and paths and then mimicking the muscle action by applying tension on the muscle during dissection. We used additional reference to a biomechanical model of an ostrich (Hutchinson et al. 2014) to refine the threedimensional actions of the hip muscles, as those actions are difficult to accurately ascertain from visual inspection and manipulation. Table 1 shows our simplified description of the anatomy, abbreviations used throughout this study, and inferred muscle actions. Figures 1 to 3 show schematic anatomical representations of the muscle anatomy.

To avoid freeze drying of the carcasses, we ensured all animals were frozen soon after euthanasia kept in sealed bags, and were not thawed and refrozen before dissection. The carcasses showed minimal autolysis and therefore an easier and better dissection during which muscle actions could be approximated without damaging their structure and attachments.

Dissection of the right pelvic limb muscles was performed in all specimens apart from the first two subjects in the 4-6 week old group, in which the muscles of the left limb were dissected first to standardise the technique. Measurements taken from the muscles of the left limb were not used (avoiding duplication of information), with the exception of when there were unidentified/damaged muscles from the right limb of the same specimen, in order to create a complete set of muscles for each specimen.

After identification of each muscle, we performed complete dissection and removal of it by transection at its origin and insertion(s). Next, the muscle was laid flat on a table and we took four muscle architectural measurements in a standard protocol: muscle mass $\left(M_{m}\right)$, fascicle length $\left(L_{f}\right)$, muscle belly length and pennation angle $(\theta)$. Muscle mass was measured on an electronic scale $( \pm 0.01 \mathrm{~g})$ after removal of tendons, fat and aponeuroses. Fascicle length was measured from at least five random sites within the muscle belly using digital callipers $( \pm 0.1 \mathrm{~mm})$. Muscle belly 
141 length was measured as the length $( \pm 1 \mathrm{~mm})$ from the origin of the most proximal

142 muscle fascicles to the insertion of the most distal fascicles into the distal tendon or

143 aponeurosis. The pennation angle was measured at least five times using a

144 goniometer $\left( \pm 5^{\circ}\right)$ with the mean of the latter measurements was taken as the

145 pennation angle for the muscle. The repeated measurements were taken from

146 multiple cuts into the muscle to expose different anatomical orientations of the

147 fascicles with the same muscle. This methodology minimises the differences that

148 may be seen across an individual muscle and ensures mean values used for further

149 calculations are representative of the overall architecture of the muscle. We

150 calculated total limb muscle mass by adding the individual masses of the muscle

151

152

153

154

155

156 bellies. Our approach was straightforward for most muscles, apart from three smaller muscles of the limb: IFI, ISF and FPPDII (Table 1), where minor dissection mistakes might have impaired estimates of their masses and architectural properties.

157

Muscle volume was calculated by dividing muscle mass by estimated muscle density of vertebrates (1.06 g cm g $^{-3}$; (Brown et al. 2003; Hutchinson et al. 2014; Mendez \&

158

159 Keys 1960)). From these data we calculated physiological cross-sectional area (PCSA) for each muscle via the standard formula (Powell et al. 1984; Sacks \& Roy 1982) (Equation 1):

$$
P C S A=\left(\frac{\text { Vmusc }}{\text { Lfasc }}\right) \cos \theta
$$

160

161

162

163

164

165

166

167
When a tendon was present it was dissected down to its insertion onto the bone together with the muscle. The tendon was then transected at the musculotendinous junction when a clear separation became apparent and stretched on a flat surface. We then measured lengths with a standard ruler or flexible measuring tape $( \pm 1 \mathrm{~mm})$, and tendon mass was also measured using the same instrumentation as for the muscles.

Tendon cross-sectional area (TCSA) was calculated using tendon length $\left(L_{\text {ten }}\right)$; from muscle origin to bony insertion; and tendon mass $\left(M_{\text {ten }}\right)$ as follows (Equation 2 ):

$$
\text { TCSA }=\frac{\text { Mten }}{1120 \text { Lten }}
$$

Where $1120 \mathrm{~kg} \mathrm{~m}^{-3}$ is assumed as the density of tendon (Hutchinson et al. 2014; Ker 1981).

170 Statistical analysis

171 Ontogenetic scaling relationships of (non-normalized) muscle properties were 172 analysed using reduced major axis ("Model II") regression for $\log _{10}$ of each property

173

174

175

176

177

178

179

180 vs $\log _{10}$ body mass using custom-designed $\mathrm{R}$ software code (R Development Core Team 2010) code. A Shapiro-Wilk test was performed to assess normality of distribution of the residuals, and the $p$ value for significance was set to $<0.05$. The inclusion criteria for data presented were: Datasets first had to have a $p$ value $<0.05$ in the above described Shapiro-Wilk test. If this $p$ was $>0.05$, the data were then tested for the presence of outliers (which were set at \pm 2 standard deviations [SD] from the mean) and outliers removed. The RMA linear regression was performed again using this dataset and again, data were only presented if the $p$ value for 
181 distribution of residuals was $<0.05$. Once the datasets were defined, $\mathrm{R}^{2}$ correlation

182 values and upper and lower bounds of the $95 \%$ confidence interval $(\mathrm{Cl})$ were

183 calculated to assess the spread of data points around each regression line.

184 In order to obtain relative values to compare results from individuals of different

185 size, muscle mass, PCSA and $\mathrm{F}_{\text {length }}$ were normalized to body mass (BM) by dividing

186 each value by the subject's $B M, B^{0.67}$ and $B M^{0.33}$ respectively. We used body mass

187 (BM) as our independent variable and the target architectural parameter as our

188 dependant variable. Overall, we followed a similar approach as that described by

189 Allen et al. $(2010,2014)$.

190 Briefly, for two objects to be considered geometrically similar (and thus for an

191 isometric scaling pattern to be inferred), areas should scale to the square product of

192 lengths and volumes to the cube of lengths. Because mass is a volumetric property,

193 the dependant variable is considered to scale isometrically if the mass of the

194 structure scales with $\mathrm{BM}^{1}$, areal properties (PCSA, TCSA) scale to $\mathrm{BM}^{0.67}$ and lengths

195 scale to $\mathrm{BM}^{0.33}$, whereas angles and other non-dimensional variables should scale as

$196 \mathrm{BM}^{0}$.

\section{Results}

198 We obtained 6524 measurements of seven different muscle-tendon architectural

199

200

201

202

203

204

205

206

207

208

209

210

211 parameters from 34 pelvic limb muscles and four pelvic limb bones in 17 emus from 3.6 to $42 \mathrm{~kg}$ of body mass. We found strong evidence for positive allometric scaling for many of these architectural parameters, as described below. To aid interpretation of our results, we have divided the muscles of the limb into proximal (those acting mostly on the hip and knee joints) and distal (those acting on the ankle, foot and digits) groups and have used this division to compare trends between the two regions.

\section{Bone lengths}

The lengths of the four bones scaled with moderate positive allometry (expected slope representing isometry would be 0.33). The femur had the least marked allometric exponent (0.38), whilst the tarsometatarsus the greatest $(0.44)$, the tibiotarsus had a slope value of 0.41 and for the $1^{\text {st }}$ phalanx of the second digit (P1) the value was 0.39 (for full results see Table 2 ).

212 Myology, architectural characteristics of muscles and functional interpretation

213 We classified a total of 34 muscles in Table 1. As noted by Regnault et al. (2014),

214 there is no patellar ossification in the knee joint of emus, unlike ostriches and some

215 other palaeognaths as well as most extant birds. Although muscle origins, insertions

216 and paths were generally found to agree with previous publications (Haughton 1867;

217 Patak \& Baldwin 1998; Vanden Berge \& Zweers 1993) and hence detailed re-

218 description is unnecessary, there were a few muscles for which we have found some

219 differences worth noting, or for which we needed to use methodological

220 simplifications:

221 M. iliotibialis lateralis pars postacetabularis (IL): The distal fusion and similar actions

222 of both parts of the IL muscle (Fig.1) meant that, in order to avoid dissection errors

223 when finding the division between the cranial and caudal parts of the muscle, we

224 measured and presented them together. 
225 M. iliotrochantericus cranialis (ITCR): Although this was a clear, separate muscle in 226 most specimens (Fig. 2), it was found to be fused with the ITM in two specimens of

227 body mass $\sim 20 \mathrm{~kg}$, which is a common finding in birds (Gangl et al. 2004)

228 M. ischiofemoralis (ISF): This small muscle is difficult to detect and dissect, which is 229 likely to have affected the accuracy of the data obtained from it (leading to lower $\mathrm{R}^{2}$ 230 values and wider $95 \% \mathrm{Cl}$ ranges). Its action is likely to involve fine motor control, 231 proprioception and stabilisation of the hip joint, given its very small size. Some 232 studies have considered this muscle to be absent (or fused with other muscles; e.g., 233 CFP) in emus (Haughton 1867; Patak \& Baldwin 1998), which would be unusual for 234 any birds. The origin and insertion of the muscle that we label the ISF (Fig. 3) is best 235 interpreted as a reduced -- but still present - muscle, similar to that in ostriches 236 (Gangl et al. 2004; Zinoviev 2006).

237 M. caudofemoralis pars pelvica (CFP): We consider, contrary to other reports 238 (Haughton 1867; Patak \& Baldwin 1998), that this muscle is present in emus (Fig. 2). 239 Prior studies classified this muscle as the "iliofemoralis" but we agree with the

240 Nomina Anatomica Avium (Vanden Berge \& Zweers 1993) and other reports (Gangl

241 et al. 2004; Hutchinson 2004a; Hutchinson et al. 2014; Zinoviev 2006) that it is

242 present in ratites, related to a reduced portion of the large caudofemoralis muscle 243 that is ancestrally present in tailed reptiles (Gatesy 1999). There is no evidence of a 244 caudalis part to the M. caudofemoralis in emus, unlike in ostriches (Gangl et al. 245 2004) and some other ratites, so this sub-division of the CFP is either fused to the 246 CFP or lost.

247 M. ambiens (AMB): We found this muscle to have two insertions, previously 248 unnoticed: a tendinous one onto the tibia and a fleshy one onto the distal femur. 249 Unusual modifications of this muscle seem common in ratite birds (Hutchinson et al. 250 2014)

251 M. popliteus: This is a short, deeply positioned, fleshy muscle with multiple fibrous 252 planes within it, originating on the caudolateral, proximal aspect of the tibiotarsus 253 and inserting onto the medial side of the proximal fibula (Fig. 3). It is likely a 254 stabiliser or pronator/supinator of the fibula, as in ostriches (Fuss 1996), and may 255 act as a proprioceptive or ligament-like structure.

\section{Normalized data for individual muscles}

To allow relative comparisons between muscle measurements, we normalized data from only the 16 month old (Group 3, adult birds) emus. Data are only presented for adult emus so as not to influence the relative proportions due to ontogenetic allometry. The entire ontogenetic data set was analysed similarly with negligible differences found, indicating that the relative patterns seen between muscles for adults are present in very young birds as well. Data for muscle mass, fascicle length and PCSA are presented in Figure 4 . The largest relative muscles with regards to mass were three proximal (ILPO, ILFB and IC) and three distal muscles (GM, FL and $\mathrm{GL}$ ). This order changes when muscles are ranked according to PCSA because parallel-fibred muscles tend to drop down the list, with the large ILPO being the only parallel-fibred muscle seen in the top 10 of a list that is otherwise dominated by distal muscles (FL, GM, GL and FPDIII). On the other hand, when fascicle length is compared, the three parts of the gastrocnemius (GIM, GM and GL) are the only distal muscles listed amongst the 10 muscles with the longest fascicles. . The four muscles with the longest fascicles are the FCLP, IC, ILFB and ILPO.

\section{Limb muscle masses}


273 Total mass values of the hindlimb musculature represented a mean of $13.4 \pm 3 \%$ of

274 BM, with the proximal limb musculature (PLM) representing $61 \pm 2 \%$ of limb muscle

275 mass and the distal limb muscles (DLM) accounting for the remaining 39 $2 \%$.

276 However, if only values for the six largest birds (adults) are analysed, limb muscle

277 mass accounts for $15 \pm 1 \%$ of BM. The limb muscle mass is only $11 \pm 3 \%$ of body mass

278 in the five birds that were 4-6 weeks old.

279 Scaling regression analysis

280 The slopes of the reduced major axis regression lines for muscle properties vs. body

281

282

283

284

285

286

287

288

289 Scaling of limb muscle masses

290 We found limb muscle mass as well as the masses of proximal (PLM) and distal limb 291 muscles (DLM) to be tightly correlated with body mass across all three groups. The 292 regression slope of limb muscle mass vs. BM was $1.16\left(1.05<\mathrm{Cl}<1.29, \mathrm{R}^{2}=0.96\right)$, 293 whilst PLM had a value of $1.14\left(1.02<\mathrm{Cl}<1.27, \mathrm{R}^{2}=0.96\right)$ and DLM exhibited a slope 294 of $1.20\left(1.09<\mathrm{Cl}<1.32, \mathrm{R}^{2}=0.97\right)$.

295

296

297

298

299

300

301

302

303

304

305 mass are shown in Tables 3 and 4 , with $\mathrm{R}^{2}$ and $95 \% \mathrm{Cls}$, as well as represented in Figures 5 ( $A$ and $B$ ) and 6 . Ranges of the slope and amplitudes of the Cls referred to below are the upper and lower bounds of the $95 \%$ Cls for the regression slopes. Scaling exponents and $\mathrm{Cls}$ are presented in Table 3. Scaling exponents and lines representing isometry are plotted in Figure 5A and 5B ( $\mathrm{M}_{m}, \mathrm{~L}_{f}$ and PCSA) and Figure 7 ( $M_{\text {ten, }} L_{\text {ten }}$ and TCSA). In summary, there was strong positive allometry of muscle mass and mild positive allometry or isometry of fascicle length, leading to a marked positive allometry of PCSA.

Consistent with the trends for the hindlimb more broadly, the individual muscles also generally showed positive ontogenetic allometry. Out of 34 muscles, 26 had slopes for $\mathrm{M}_{\mathrm{m}} \mathrm{Vs}$. BM with their lower $\mathrm{Cl}$ limit >1 (consistent with positive allometry), and only eight (ITCr, ITM, IFI, ISF, FCLA, FMTL, AMB and FPPDII) had a lower CI boundary for the regression slope lower than 1 (indicating potential negative allometry). Of the 26 muscles showing positive allometry of $M_{m}$, we found strong positive allometry (regression slopes with the lower boundary of the $\mathrm{Cl}$ greater than 1.1) in 18/34.

Similarly, scaling patterns of the muscle masses for the USA group of emus (Figure 6), showed similar scaling patterns to the UK group, with only five muscles having a lower $\mathrm{Cl}$ boundary $<1$ (POP, ILPO, FPDIV, OBTII and FPDII) and the remaining having their Cls entirely within positive allometry values.

306 Scaling of muscle fascicle length

307 In general, fascicle length $\left(L_{f}\right)$ was only moderately well correlated with body mass 308 due to substantial variation in the data (a combination of inevitable measurement 309 errors, sampling bias and true biological variation, as usual for muscle fascicle 310 measurements (e.g., Allen et al. [2010,2014]) The datasets for four muscles (ISF, 311 PIFLM, FPDII and FPPDII) had a $p$ value $>0.05$, so these are not presented (Table 3). 312 Of the remaining 30 muscles, only $16 / 30$ had $R^{2}$ values $>0.5$. Scaling of $L_{f} v s$. $B M$ 313 showed a trend towards positive allometry for $18 / 30$ muscles (lower limit of the 314 slope's $\mathrm{Cl}>0.33$ ), and for the remaining 12 muscles a slope of 0.33 was included in 315 the Cls, so isometry could not be ruled out.

316 Scaling of muscle PCSA

317 The lower boundary of the $\mathrm{Cls}$ of the scaling slope was greater than 0.66 (i.e., 318 exhibiting positive allometry) for 27 muscles and a value $<0.66$ (suggesting a 
319 potential negative allometry of muscle PCSA in emus) was obtained for eight

320 muscles (ITM, ITC, IFI, FMTL, AMB, TC and FPPDII) (Table 3).

321 Scaling of tendon mass

322 We recorded tendon characteristics for 28 muscles (Table 4); the six muscles

323 excluded did not have a discrete tendon at either of their attachments (CFP, FCLA,

324 FCLP, IC, PIFLM, POP). We encountered difficulties in achieving a consistent method

325 for tendon dissection and measurement of muscles with thin (IFE, AMB), very short

326 (ISF and IFI) or multiple tendons (FMTM, FMTIM), which lead us to exclude data from

327 these as well. The tendon of the GIM was included with the GM tendon, and the

328 FMTL tendon was not measured because the muscle was transected at the proximal

329 aspect of the large patellar tendon for studies of patellar tendon morphology by

330 Regnault et al. (2014). Thus data are presented for the tendons of 20 muscles. The

331 major gastrocnemius tendon resulting from the fusion of the tendons of the three

332 gastrocnemius muscles was dissected by transecting the tendon of the GL at the

333 site of fusion onto the common tendon; therefore the GM remained with the

334 extensive common portion of the tendon, which distally was transected at its

335 insertion onto the fibrous scutum at the level of the ankle joint.

336 The scaling slopes for tendon mass indicate positive allometry in 10 out of 20

337 tendons (lower $\mathrm{Cl}$ boundary $>1$ ) across emu ontogeny. The masses for the remaining

338 ten tendons scaled with isometry (lower $\mathrm{Cl}<1.0$, upper $\mathrm{Cl}>1.2$ )..

339 Scaling of tendon length

340 We measured $L_{\text {ten }}$ for the same 20 muscles for which we obtained tendon masses

341 (Table 4), from the end of the muscle belly to the insertion. Statistical analysis of

342 one muscle (ITCr) led to exclusion of this muscle because the $p$ value was $>0.05$. For

343 the other 19 tendons, the general scaling trend was towards strong positive

344 allometry, with 16 muscles having the lower limit of the $\mathrm{Cl}>0.33$. In three muscles

345 (FCM, GM, FL), the lower $\mathrm{Cl}$ for tendon length was <0.33, indicating isometry for

346 length in these tendons. Given these patterns, we infer a general trend for positive

347 allometry of tendon length in growing emus.

348 Scaling of tendon cross-sectional area

349 Average TCSA was calculated for the same 20 tendons as above (Table 4). The

350 dataset for ILPO had a $p$ value $>0.05$ and was excluded. Of the 19 remaining

351 tendons, 10 showed a lower $\mathrm{Cl}$ limit of the slope consistent with positive allometry

352 (>0.66). The remaining nine tendons showed ontogenetic isometry for TCSA.

\section{Discussion}

354 Emus, like other ratites and other precocial birds, must have locomotor

355 independence from hatching and develop into large, running adult birds within 16-18

356 months (Davies \& Bamford 2002). Taking into consideration their initial development

357 within the egg, their ontogeny poses interesting questions about their locomotor

358 development, related to our study's aims, such as: How do muscle structure and

359 anatomy change to accommodate precocial development in emus? What are the

360 strategies that growing emus use to maintain tissue mechanical safety factors

361 during rapid development of cursorial morphology and high-speed locomotor

362 abilities? Our data suggest some answers to these questions, as follows.

363 Scaling patterns across ontogeny 
364 We found positive allometry of emu pelvic limb muscle masses, indicating that most 365 muscles get become significantly more powerful (in relative and absolute terms) as the animals grow. However, the functional relevance of this observation is slightly mitigated by a less marked positive allometry of PCSA (and therefore maximal muscle force), driven by a trend for fascicle length that is closer to isometry (i.e., preserving geometric similarity).

370 In the proximal part of the pelvic limb of emus, the developmental and functional 371 mechanics appear to rely on the arrangement of large and metabolically expensive 372 muscles (ILPO, ILFB, IC, FCLP and FMTL) to provide the wide range of motion of the 373 knee joint (and hip, during faster running) in combination with a relatively short 374 femur that scales close to isometry. This arrangement also leads to a proximal to 375 distal gradient of muscle mass, which has been previously reported for other birds 376 (Paxton et al. 2010; Smith et al. 2006) and has long been thought to favour energy377 savings by keeping the distal end of the limb light and its muscles dependent on 378 springy tendons. The proximal-distal gradient also concentrates large, powergenerating muscles in the proximal limb (Alexander 1974; Alexander 1991) with large moment arms (Hutchinson et al. 2014; Smith et al. 2007) and thus the ability to produce the considerable joint moments needed for high-speed running (Hutchinson 2004a,b).

\section{The distal limb, on the other hand, is heavily dependent on the triad of $\mathrm{M}$.} gastrocnemius (GL, GIM and GM) along with $\mathrm{M}$. fibularis longus ( $\mathrm{FL}$ ); both ankle extensors; as well as M. tibialis cranialis (TC) and M. extensor digitorum longus (EDL); both ankle flexors. Combined, these muscles constitute $80 \%$ of the muscle mass and $60 \%$ of the force-generating capacity (PCSA) of this portion of the limb. The unusual proportion of body mass taken up by the ankle extensors has been noted before (Hutchinson 2004a) and is likely an ancestral characteristic of birds (e.g., Paxton et al. 2010) but is taken to an extreme in large ratites (e.g., Smith et al. 2006).

Further distally, the long and slender tarsometatarsus bone lends itself well as a support for the long tendons of the digital flexor muscles which in turn provide essential springs used in support and propulsion of the limbs and body. The relatively small muscles and long tendons of the digital flexors make them likely to operate mainly as energy storage devices at faster speeds, as seen in other species like horses and smaller running birds (Biewener 1998; Daley \& Biewener 2011). The positive allometry of many tendon properties in emus is in line with this increase in force-generating capacity seen during ontogeny. As in most other birds, the tendons running along the tarsometatarsus are almost exclusively on the cranial and caudal (dorsal/plantar) side. It would also be interesting to know the effect on bone strains from this "bow and arrow" anatomical arrangement between the tarsometatarsus and the dorsal/plantar tendons to see if it influences the predominantly torsional loads experienced by the two proximal pelvic limb bones (Main \& Biewener 2007).

For these spring-like tendons, a trade-off between muscle force and tendon elasticity does not seem to occur in emus. This lack of a trade-off is indicated by the similar scaling patterns of the cross-sectional areas of the digital flexor muscles and tendons, both of which trend towards positive allometry across emu ontogeny. As seen in other species (Ker et al. 1988), the relative increases in the cross-sectional areas of tendons might maintain tendon safety factors (maximal stresses before failure vs. in vivo maximal stress) as emus increase in size. However, tendons might also change their biomechanical properties (Young's modulus) with age, as seen in 
413 other species (Shadwick 1990; Thorpe et al. 2014), therefore influencing

414 biomechanical interpretations of the data presented here. Without measuring

415 tendon elastic modulus with age, it is difficult to interpret how tendon stiffness and

416 safety factor might change with age in emus.

417 To complement data from a prior study showing the scaling patterns of the cross-

418 sectional areas of the femur and tibiotarsus of emus to be close to isometry (Main \&

419 Biewener 2007), here we analysed the scaling patterns of the lengths of the three

420 longest limb bones and the first phalanx of the third toe. Our data indicate positive

421 allometry of the two longer bones, the tibiotarsus (lower $\mathrm{Cl}$ limit $=0.37$ ) and

422 tarsometatarsus (lower $\mathrm{Cl}$ limit $=0.39$ ), but a less marked positively allometric

423 scaling trend for the femur (lower limit of $\mathrm{Cl}=0.34$ ) and for the first phalanx of digit

424 III (lower $\mathrm{Cl}$ limit=0.33). These results differ from those reported for another ratite,

425 the greater rhea (Rhea americana), in which only the tarsometarsus showed positive

426 allometry (Picasso 2012a) but interestingly are in line with general interspecific

427 scaling exponents found for pelvic limb bone lengths across different species of

428 palaeognaths (Cubo \& Casinos, 1996). Considering our results, if similar cross-

429 sectional geometry is assumed along the length of the bone shafts, this would lead

430 to an increase in strains (at least in bending, due to larger moments) at the mid-

431

432

433

434

435

436

437

shaft with increasing body mass. However, changes in cross-sectional areal

geometry have been shown to lead to slight positive allometry of the cross-sectional

geometry of avian limb bones across species (Doube et al. 2012) and

ontogenetically (Main \& Biewener 2007). As these geometrical changes might not

suffice to explain the increases in strain magnitudes seen during ontogeny, they

leave unexplained the role of internal forces (of soft tissues) on bone mechanics and consequently their influence on bone morphology during growth.

438 Although there are very limited data on the ontogeny of skeletal muscle physiology, 439 experiments in mice and cats (Close 1964; Close \& Hoh 1967) demonstrate that

440

441

442

443

444

445

446

447

448

449

450

451

452

453

454

455

456

457

458

459

460

461

462 although muscle force: velocity parameters change from newborns to adults, these changes appear to occur in a relatively short period and therefore newborn muscle, after the first few days of life, becomes similar to that of adults. However, mice and cats, like many other mammals, are born with neuromotor immaturity (Muir 2000), in contrast to emus. It is therefore reasonable to speculate that, like other birds (Gaunt \& Gans 1990), emus are unlikely to have appreciable changes in muscle physiology during growth. Thus changes in functional (e.g., maximal forcegenerating capacity) and biomechanical parameters should be detectable by anatomical studies such as ours.

Few studies have quantified the ontogenetic scaling patterns of limb musculature in birds (Carrier \& Leon 1990; Dial \& Carrier 2012; Paxton et al. 2014; 2012b; Picasso 2014), but positive allometry predominates in the muscle masses involved in the major adult mode of locomotion (flying vs. cursorial). In the Californian gull, the M. gastrocnemius scaled isometrically but the M. pectoralis had strong positive allometry with an inflection point when the fledglings started exercising their wings (Carrier \& Leon 1990). Paxton et al. (2014; also 2010) recently reported the ontogenetic scaling patterns of the musculature of a highly modified galliform, the broiler chicken. These birds, unsurprisingly due to their selective breeding, were found to have positive allometry of muscle masses of the main pelvic limb muscles but isometry of the fascicle lengths (Paxton et al. 2014), a pattern that is nonetheless similar to our findings. Picasso et al. (2012b) found quite similar scaling patterns across rhea ontogeny: an average 64 -fold increase in pelvic limb muscle mass from 1 month of age to adulthood whilst only a 34-fold increase in body mass. 
463 In a later study, where scaling exponents were calculated, a more generalised 464 positively allometric scaling was found in these South American ratites compared to 465 466 467 emus: with all muscle masses but two (where isometry was evident) scaling with positive allometry (slopes $\sim 1.3$ ). Total limb muscle mass of rheas scaled with an exponent of 1.18 (Picasso 2014), which is similar to our value of 1.16 .Together, these data suggest that positive allometry prevails across ontogeny for leg muscles in extant birds with precocial development; potentially a homologous feature of their development that is quite unlike the isometry prevailing in their closest extant relatives, Crocodylia (Allen et al., 2010,2014).

472 Dial and Carrier (2012) suggested that birds must optimise their energy

473 consumption to achieve their ultimate functional gait whilst channelling resources to 474 their precocial gait (Dial \& Carrier 2012) (running vs. swimming or flying). Ratites 475 are unusual for birds in that they solely have terrestrial gaits throughout their life 476 and, in the case of emus, their wings have atrophied to such an extent that they 477 should not present much metabolic competition to hindlimb development.

478 Considering the approximately isometric overall scaling of kinematic parameters

479

480

481

482

483

484

485 (e.g., stride lengths, stride frequencies, duty factors) seen in ratites (Main \& Biewener 2007; Smith et al. 2010), it is likely that this increase in muscle masses will lead to a limb that is adapted for power production and perhaps (considering our less allometric tendon results) elastic energy storage/return. The former is also supported by metabolic studies which found a predominance of fast fibres in the $M$. gastrocnemius of adult emus (Patak 1993), although more studies of muscle physiology in emus and other ratites would be valuable.

486

487

488

489

490

491

492

493

494

495

496

497

498

499

The need for locomotor independence and high performance in vulnerable, young, precocial and cursorial birds might favour allometry of muscle architecture (Carrier 1996). If so, could adult muscle phenotypes be a reflection of the locomotor needs during early development and therefore be overdesigned for their demands? Alternatively, negative allometric scaling in the musculoskeletal system may occur as seen in goats (Main \& Biewener 2004) and jackrabbits (Carrier 1983). It is hard to draw an inference from our data, because the overall positive allometry seen in the pelvic limb musculature could indicate a necessity to grow faster and stronger to adulthood to compensate for a juvenile disadvantage or could reflect selective pressures on the locomotor ontogeny of emus in which muscles congenitally primed for fast growth during adolescence could lead to continued growth past an optimum in adulthood. Although direct measurements of maximal performance of complex locomotor systems is problematic, a modelling approach using the data presented here could be a valid approach to answer this question.

500 How well are farmed emus representative of the species overall?

501 Although emu farming is relatively common, its goal is to extract meat, oil and skin 502 and therefore these birds are not bred in captivity for their locomotor behaviour, nor 503 do they suffer strong predatory pressures on it. The diet of captive bred birds as well 504 as their relative sedentary regime when compared to wild animals is likely to 505 influence tissue development and distribution. However, as farming of these birds is 506 a recent activity and it is not a highly specialised or intense process as with other 507 domesticated species (Goonewardene et al. 2003), it is unlikely that heritable traits 508 of the emu musculoskeletal system have been significantly altered. Therefore, we 509 expect the muscle distribution and scaling patterns of our emus to be similar to wild 510 emus. 
511 By presenting muscle mass data from two distinct groups of birds (UK and USA

512 groups), we established that these groups at least have similar scaling patterns,

513 ruling out any potential bias imposed by different breeding regimes. With regards to

514 diet, it was apparent that our birds were carrying a significant amount of

515 subcutaneous and peritoneal fat; likely encouraged by their ad libitum access to a

516 commercial pelleted diet. The influence of body fat on our scaling results is hard to

517 test with the available data, but Hutchinson et al. (2014) noted a possible reduction

518 in relative muscle masses in wild vs. captive bred ostriches, which could also apply

519 to emus. Regardless, it is less certain that the scaling patterns for muscle/tendon

520 architecture observed here would differ in wild vs. captive emus.

521

522

523

524

525

526

527

528

529

530

531

532

533

534

535

536

537

538

539

540

541

542

543

544

545

546

\section{Conclusions}

We have provided a new dataset on the ontogenetic scaling of pelvic limb anatomy and muscle architectural properties of a cursorial bird (the first complete architectural dataset of its kind), and we have done this using a group of 17 emus across a tenfold increase in body mass. A marked trend of positive allometry of muscle masses and PCSAs is accompanied by less marked positive allometry of fascicle lengths. Tendons, specially the long digital flexors, also demonstrate positive allometry of their lengths, as do the two longer limb bones (tibiotarsus and tarsometatarsus). We have illuminated the ontogenetic adaptation of the musculoskeletal system in an extreme example of size variation during rapid growth. Our dissections refined the myology of the pelvic limb in emus (Table 1 and Figures 1-3) and found some anatomical aspects that were previously misunderstood. This is important, as functional studies depending on inaccurate anatomical accounts of the myology could obtain unrealistic results from biomechanical models using such data (Goetz et al. 2008; Hutchinson et al. 2014). This work should be a valuable resource for future functional, comparative and evolutionary studies of emus, other birds and extinct related animals.

\section{Acknowledgements}

We thank Jack Machale, Emily Sparkes, Kyle Chadwick, Charlotte Cullingford, Sophie Regnault and Chris Basu who helped with the dissections. Craig McGowan provided assistance with muscle dissections in the USA emu sample. A special thank you goes to Vivian Allen for providing the custom designed $\mathrm{R}$ code that we used to perform the regression analysis, as well as valuable intellectual discussions. We also thank Ashley Heers and Diego Sustaita as well as an anonymous reviewer and reviewer Trevor Worthy for their helpful comments on an earlier draft of this manuscript. 


\section{References}

548 Abourachid A. 2000. Bipedal locomotion in ratites (Paleognatiform): examples of 549 cursorial birds. Ibis:538-549.Alexander R. 1974. Mechanics of jumping by a dog 550 Canis familiaris. Journal of Zoology 173:549-573.

551

552

553

554

555

556

557

558

559

560

561

562

563

564

565

566

567

568

569

570

571

572

573

574

575

576

577

578

579

580

581

582

583

584

585

586

587

588

589

590

591

592

593

594

595

596

597

Alexander R. 1991. Energy saving mechanisms in walking and running. Journal of Experimental Biology 160:55-69.

Alexander R, Jayes A, Maloiy GM, and Wathuda E. 1979. Allometry of the limb bones of mammals from shrews (Sorex) to elephant (Loxodonta). Journal of Zoology 189:305-314.

Allen V, Elsey RM, Jones N, Wright J, and Hutchinson JR. 2010. Functional specialization and ontogenetic scaling of limb anatomy in Alligator mississippiensis. Journal of Anatomy 216:423-445.

Allen, V., Molnar, J., Parker, W., Pollard, A., Nolan, G. and Hutchinson, J. R. (2014), Comparative architectural properties of limb muscles in Crocodylidae and Alligatoridae and their relevance to divergent use of asymmetrical gaits in extant Crocodylia. Journal of Anatomy 225:569-582.

Bertram JE, and Biewener A. 1990. Differential scaling of the long bones in the terrestrial Carnivora and other mammals. Journal of Morphology 204:157-169.

Biewener A. 1998. Muscle-tendon stresses and elastic energy storage during locomotion in the horse. Comparative Biochemistry and Physiology B 120:7387.

Biewener A.. 1982. Bone strength in small mammals and bipedal birds: do safety factors change with body size? Journal of Experimental Biology 98:289-301.

Brown NT, Pandy MG, Kawcak CE, and Mcllwraith CW. 2003. Force- and momentgenerating capacities of muscles in the distal forelimb of the horse. Journal of Anatomy 203:101-113.

Carrier D, and Leon L. 1990. Skeletal growth and function in the California gull (Larus californicus). Journal of Zoology 222:375-389.

Carrier DR. 1996. Ontogenetic limits on locomotor performance. Physiological Zoology 69:467-488.

Carrier R. 1983. Postnatal ontogeny of the musculo-skeletal system in the blacktailed jackrabbit (Lepus californicus). Journal of Zoology 201:27-55.

Close B. 1964. Dynamic properties of fast and slow skeletal muscles of the rat during development. Journal of Physiology 173:74-95.

Close B, and Hoh J. 1967. Force:velocity properties of kitten muscles. Journal of Physiology 192:815-822.

Cubo J, and Casinos A. 1996. Flightlessness and long bone allometry in Palaeognathiformes and Sphenisciformes. Netherlands Journal of Zoology 47:209-226.

Daley MA, and Biewener AA. 2011. Leg muscles that mediate stability: mechanics and control of two distal extensor muscles during obstacle negotiation in the guinea fowl. Philosophical Transactions of the Royal Society of London B: Biological Sciences 366:1580-1591.

Davies SF, and Bamford M. 2002. Ratites and Tinamous: Tinamidae, Rheidae, Dromaiidae, Casuariidae, Apterygidae, Struthionidae: Oxford University Press.

Dial KP, and Jackson BE. 2011. When hatchlings outperform adults: locomotor development in Australian brush turkeys (Alectura lathami, Galliformes). Proceedings of the Royal Society B: Biological Sciences 278:1610-1616.

Dial TR, and Carrier DR. 2012. Precocial hindlimbs and altricial forelimbs: partitioning ontogenetic strategies in mallards (Anas platyrhynchos). Journal of Experimental Biology 215:3703-3710. 
598 Doube M, Yen SC, Klosowski MM, Farke AA, Hutchinson JR, and Shefelbine SJ. 2012.

599

600

601

602

603

604

605

606

607

608

609

610

611

612

613

614

615

616

617

618

619

620

621

622

623

624

625

626

627

628

629

630

631

632

633

634

635

636

637

638

639

640

641

642

643

644

645

646

647

648

649

Whole-bone scaling of the avian pelvic limb. Journal of Anatomy 221:21-29.
Fuss FK. 1996. Tibiofibular junction of the South African ostrich (Struthio camelus australis). Journal of Morphology 227:213-226.

Gangl D, Weissengruber GE, Egerbacher M, and Forstenpointner G. 2004. Anatomical description of the muscles of the pelvic limb in the ostrich (Struthio camelus). Anatomia Histologia Embryologia 33:100-114.

Gatesy SM. 1999. Guineafowl hind limb function. II: Electromyographic analysis and motor pattern evolution. Journal of Morphology 240:127-142.

Gatesy SM, and Biewener AA. 1991. Bipedal locomotion: Effects of speed, size and limb posture in birds and humans. Journal of Zoology 224:127-147.

Gaunt A, and Gans C. 1990. Architecture of chicken muscles: short-fibre patterns and their ontogeny. Proceedings of the Royal Society of London B: Biological Sciences 240:351-362.

Gillooly JF, Brown JH, West GB, Savage VM, and Charnov EL. 2001. Effects of size and temperature on metabolic rate. Science 293:2248-2251.

Goetz JE, Derrick TR, Pedersen DR, Robinson Da, Conzemius MG, Baer TE, and Brown TD. 2008. Hip joint contact force in the emu (Dromaius novaehollandiae) during normal level walking. Journal of Biomechanics 41:770-778.

Goonewardene LA, Wang Z, Okine E, Zuidhof MJ, Dunk E, and Onderka D. 2003. Comparative growth characteristics of emus (Dromaius novaehollandiae). Journal of Applied Poultry Research 12:27-31.

Haughton S. 1867. The muscular anatomy of the emu (Dromaius novaehollandiae). Proceedings of the Royal Irish Academy 9:487-497.

Hemmingsen AM. 1960. Energy metabolism as related to body size and respiratory surfaces, and its evolution. Steno Memorial Hospital and Nordinsk Insulin Laboratorium 9:6:110.

Hokkanen JE. 1986. The size of the largest land animal. Journal of Theoretical Biology 118:491-499.

Hutchinson JR. 2004a. Biomechanical modeling and sensitivity analysis of bipedal running ability. I. Extant taxa. Journal of Morphology 262:421-440.

Hutchinson JR. 2004b. Biomechanical modeling and sensitivity analysis of bipedal running ability. II. Extinct taxa. Journal of Morphology 262:441-461.

Hutchinson JR, Rankin J, Rubenson J, Rosenbluth K, Siston R, and Delp S. 2014. Musculoskeletal modeling of an ostrich (Struthio camelus) pelvic limb: Influence of limb orientation on muscular capacity during locomotion. PeerJ PeerJ PrePrints 2:e513v1 http://dx.doi.org/10.7287/peerj.preprints.513v1 (in review).

Ker R. 1981. Dynamic tensile properties of the plantaris tendon of sheep (Ovis aries). Journal of Experimental Biology 93:283-302.

Ker RF, Alexander R, and Bennet M. 1988. Why are mammalian tendons so thick? Journal of Zoology 216:309-324.

Kleiber M. 1932. Body size and metabolism. Hilgardia 6:311-353.

LaBarbera M. 1989. Analyzing body size as a factor in ecology and evolution. Annual Review of Ecology and Systematics 20:97-117.

Main RP, and Biewener AA. 2004. Ontogenetic patterns of limb loading, in vivo bone strains and growth in the goat radius. Journal of Experimental Biology 207:2577-2588.

Main RP, and Biewener AA. 2007. Skeletal strain patterns and growth in the emu hindlimb during ontogeny. Journal of Experimental Biology 210:2676-2690.

Maloiy GM, Alexander RM, Njau R, and Jayes AS. 1979. Allometry of the legs of running birds. Journal of Zoology 187:161-167. 
650

651

652

653

654

655

656

657

658

659

660

661

662

663

664

665

666

667

668

669

670

671

672

673

674

675

676

677

678

679

680

681

682

683

684

685

686

687

688

689

690

691

692

693

694

695

696

697

698

699

700

701

702

McMahon T. 1975. Allometry and biomechanics: limb bones in adult ungulates. American Naturalist 109:547-563.

Mendez J, and Keys A. 1960. Density and composition of mammalian muscle. Metabolism-Clinical and Experimental 9:184-188.

Miller CE, Basu C, Fritsch G, Hildebrandt T, and Hutchinson JR. 2008. Ontogenetic scaling of foot musculoskeletal anatomy in elephants. Journal of the Royal Society, Interface 5:465-475.

Minnaar P, and Minnaar M. 1998. The Emu Farmer's Handbook: Induna Company.

Muir GD. 2000. Early ontogeny of locomotor behaviour: a comparison between altricial and precocial animals. Brain Research Bulletin 53:719-726.

Patak A. 1993. Structural and metabolic characterization of the muscles used to power running in the emu (Dromaius novaehollandiae), a giant flightless bird. Journal of Experimental Biology 249:233-249.

Patak A, and Baldwin J. 1998. Pelvic limb musculature in the emu Dromaius novaehollandiae (Aves: Struthioniformes: Dromaiidae): adaptations to highspeed running. Journal of Morphology 238:23-37.

Paxton H, Anthony NB, Corr SA, and Hutchinson JR. 2010. The effects of selective breeding on the architectural properties of the pelvic limb in broiler chickens: a comparative study across modern and ancestral populations. Journal of Anatomy 217:153-166.

Paxton H, Tickle P, Rankin J, Codd J, and Hutchinson J. 2014. Anatomical and biomechanical traits of broiler chickens across ontogeny. Part II. Body segment inertial properties and muscle architecture of the pelvic limb. Peerj 2:e473.

Picasso MBJ. 2012a. Postnatal ontogeny of the locomotor skeleton of a cursorial bird: greater rhea. Journal of Zoology 286:303-311.

Picasso MBJ, Tambussi CP, Mosto MC, and Degrange FJ. 2012b. Crescimiento de la masa muscular del miembro posterior del Ñandu Grande (Rhea americana) durante la vida postnatal. Revista Brasileira de Ornintologia 20:1-7.

Picasso MBJ. 2014. Ontogenetic scaling of the hindlimb muscles of the Greater Rhea (Rhea americana). Anatomia, Histologia, Embryologia, published online.

Powell PL, Roy RR, Kanim P, Bello MA, and Edgerton VR. 1984. Predictability of skeletal muscle tension from architectural determinations in guinea pig hindlimbs. Journal of Applied Physiology 57:1715-1721.

Regnault S, Pitsillides AA, and Hutchinson JR. 2014. Structure, ontogeny and evolution of the patellar tendon in emus (Dromaius novaehollandiae) and other palaeognath birds. PeerJ PrePrints 2:e404v1

R Development Core Team. 2010. R: A language and environment for statistical computing. Vienna, Austria: R Foundation for Statistical computing.

Sacks RD, and Roy RR. 1982. Architecture of the hind limb muscles of cats: functional significance. Journal of Morphology 173:185-195.

Schmidt-Nielsen K. 1984. Scaling: Why is Animal Size so Important? Cambridge University Press.

Shadwick RE. 1990. Elastic energy storage in tendons: Mechanical differences related to function and age. Journal of Applied Physiology 68:1033-1040.

Smith N, Wilson A, Jespers K, and Payne R. 2006. Muscle architecture and functional anatomy of the pelvic limb of the ostrich (Struthio camelus). Journal of Anatomy 209:765-779.

Smith NC, Jespers KJ, and Wilson A. 2010. Ontogenetic scaling of locomotor kinetics and kinematics of the ostrich (Struthio camelus). Journal of Experimental Biology 213:1347-1355.

Smith NC, Payne RC, Jespers KJ, and Wilson AM. 2007. Muscle moment arms of pelvic limb muscles of the ostrich (Struthio camelus). Journal of Anatomy 211:313324. 
703

704

705

706

707

708

709

710

711

712

713

714

715

716

717

718

719

720

721

722

723
Smith NC, and Wilson AM. 2013. Mechanical and energetic scaling relationships of running gait through ontogeny in the ostrich (Struthio camelus). Journal of Experimental Biology 216:841-849.

Taylor RC, Maloiy GMO, Weibel ER, Langman VA, Kamau JMZ, Seeherman HJ, and Heglund NC. 1981. Design of the mammalian respiratory system. III. Scaling maximum aerobic capacity to body mass: Wild and domestic mammals. Respiration Physiology 44:25-37.

Thorpe CT, Riley GP, Birch HL, Clegg PD, and Screen HR. 2014. Fascicles from energy-storing tendons show an age-specific response to cyclic fatigue loading. Journal of the Royal Society Interface 11.

Vanden Berge J, and Zweers G. 1993. Myologia. In: Baumel J, King A, Breazile J, Evans $\mathrm{H}$, and Vanden Berge J, eds. Handbook of Avian Anatomy: Nomina Anatomica Avium. Cambridge, MA: Nuttall Ornithological Club, pp189-247.

Yoshikawa T, Mori S, Santiesteban AJ, Sun TC, Hafstad E, Chen J, and Burr DB. 1994. The effects of muscle fatigue on bone strain. Journal of Experimental Biology 188:217-233.

Young JW. 2009. Ontogeny of joint mechanics in squirrel monkeys (Saimiri boliviensis): functional implications for mammalian limb growth and locomotor development. Journal of Experimental Biology 212:1576-1591.

Zinoviev A. 2006. Notes on the hind limb myology of the Ostrich (Struthio camelus). Ornithologia 33:53-62. 
1

Schematic anatomical representation of Emu pelvic limb anatomy

Schematic anatomical representation of the most superficial layer of muscles, in lateral view, of the pelvic limb of an adult emu. 


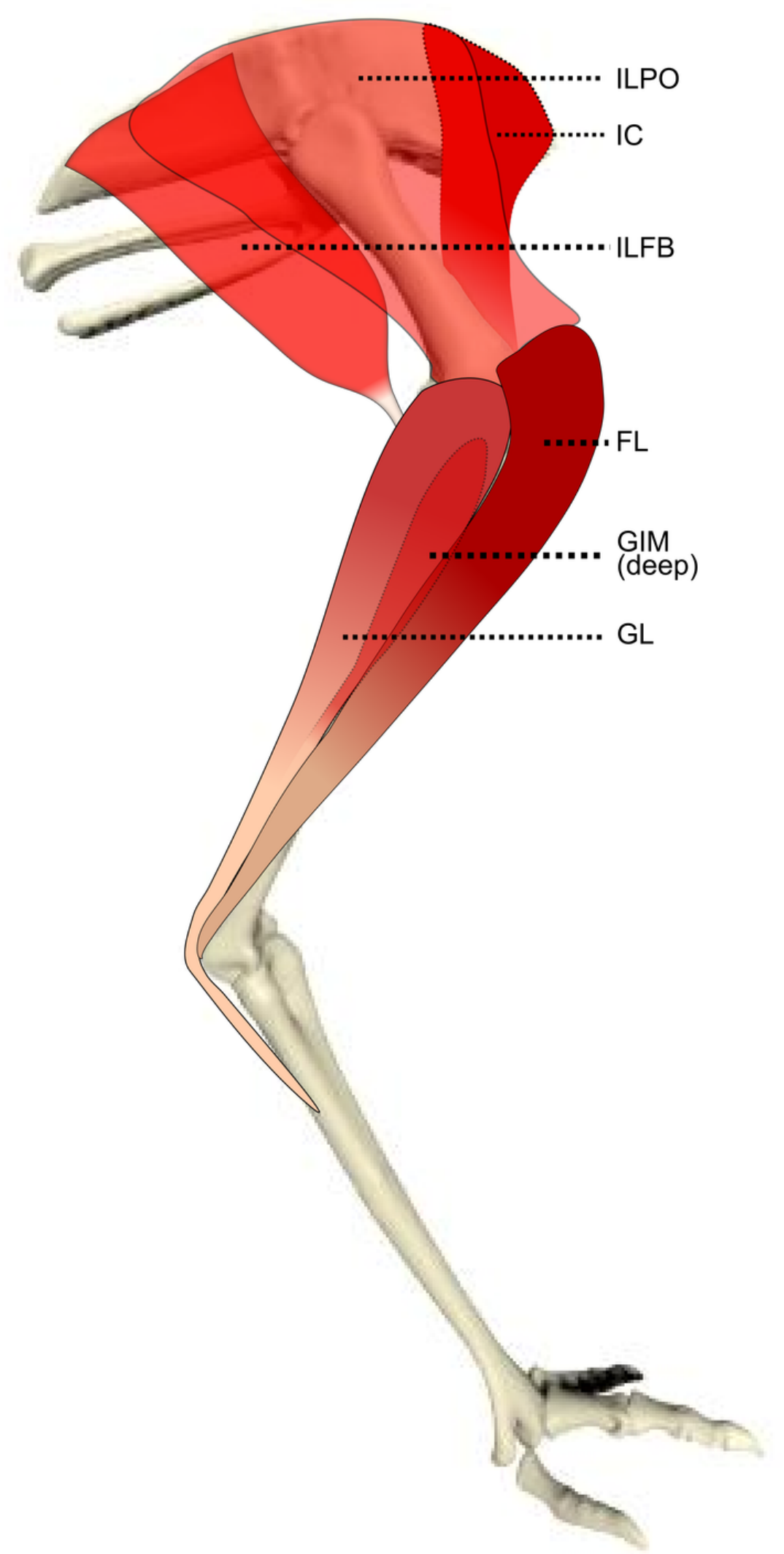


2

Schematic anatomical representation of Emu pelvic limb anatomy

Schematic anatomical representation of the intermediate layer of muscles, from a lateral view, of the pelvic limb of an adult emu. 


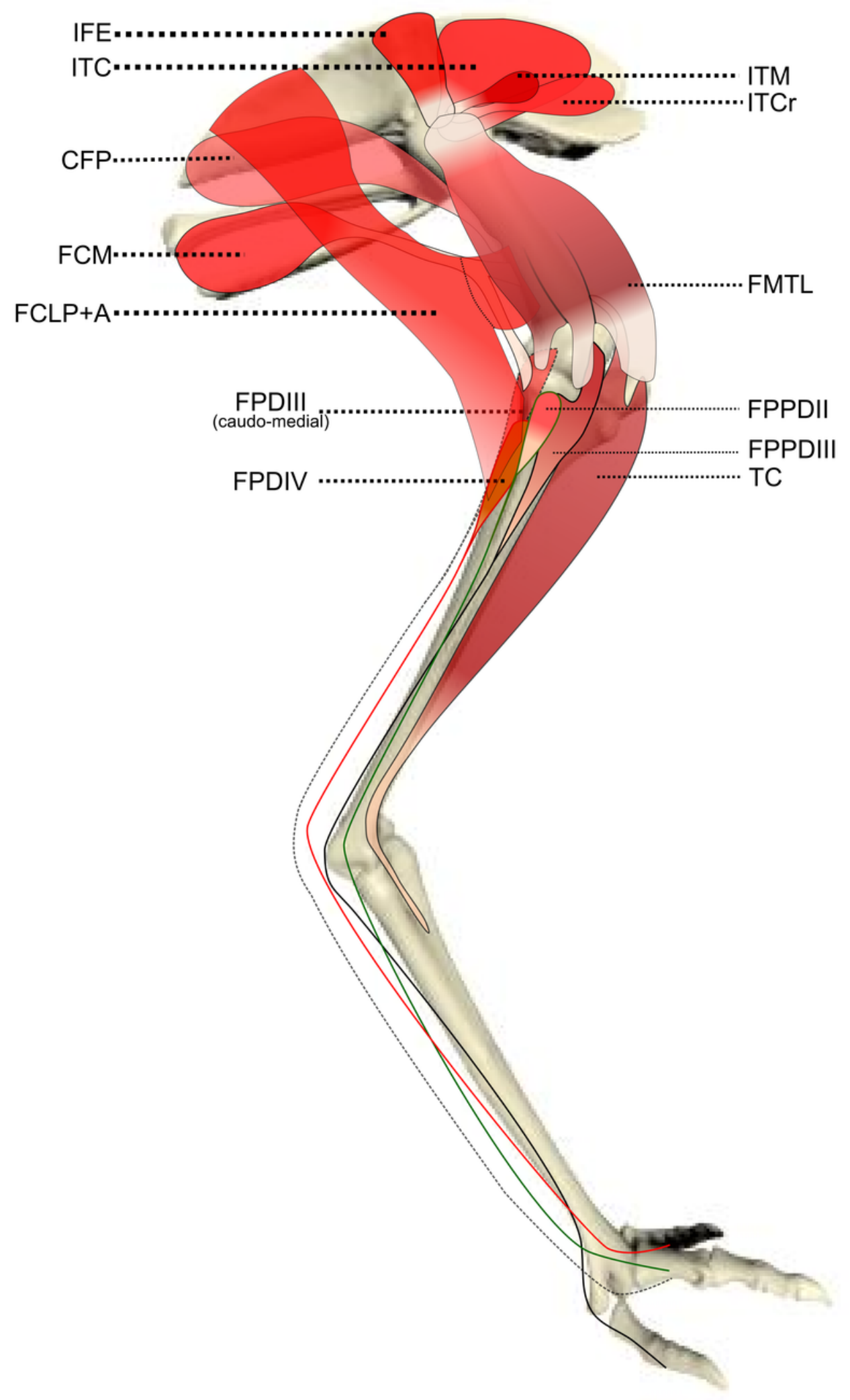


3

Schematic anatomical representation of Emu pelvic limb anatomy

Schematic anatomical representation of the deeper layer of muscles, from a lateral view, of the pelvic limb of an adult emu. 


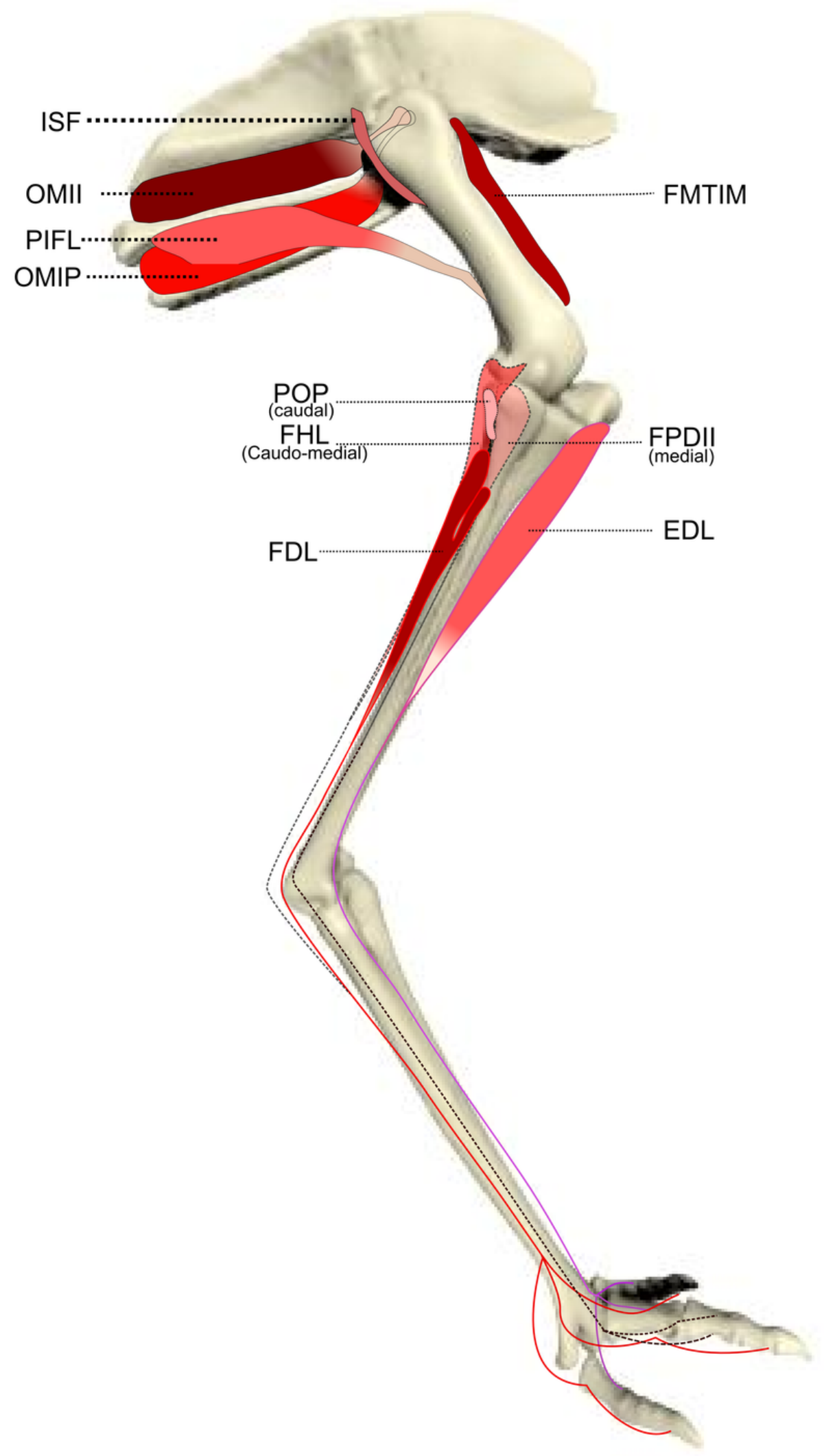




\section{4}

Normalized data: 16 month old group only

Normalized relative muscle parameters for individual muscles in emu pelvic limbs of the 16 month old birds only (Group 3; mean body mass $38.5 \mathrm{~kg}$ ); mean values (error bars showing \pm 1 S.D.) are shown. Abbreviations for muscles are in Table 1. The key on the right side of the figure shows how muscle mass $\left(M_{m}\right)$, physiological cross-sectional area (PCSA), and fascicle length $\left(L_{f}\right)$ were normalized. $L_{f}$ values were adjusted to be $1 / 10$ of the actual results in order to be of similar magnitude to the others. Muscles are organised from top to bottom in decreasing order of muscle mass. 


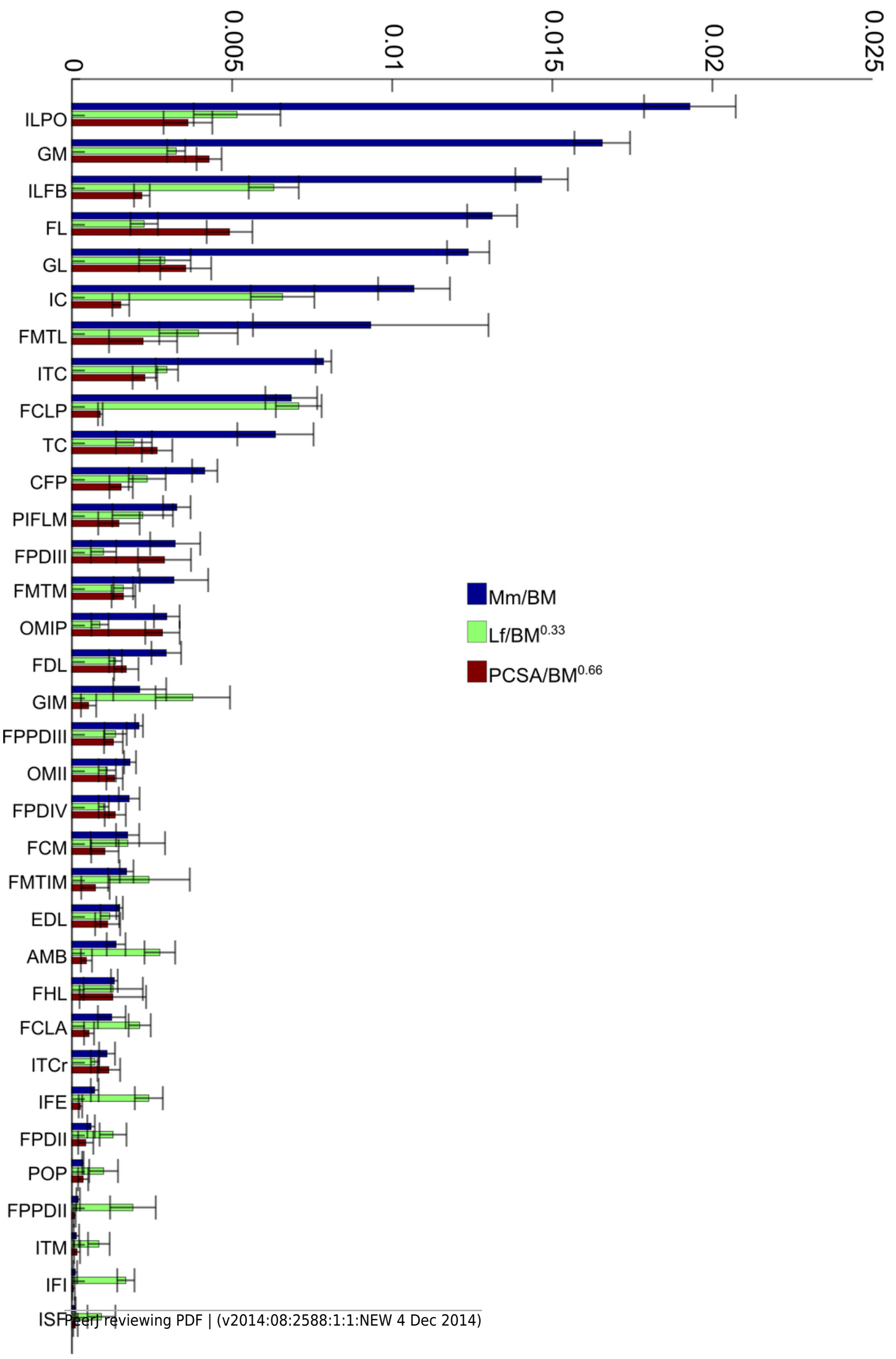




\section{5}

Ontogenetic scaling exponents of muscle properties

Ontogenetic scaling exponents and 95\% confidence intervals (shown as error bars around mean exponent) for muscle mass (red), PCSA (blue) and fascicle length (green) for individual muscles in emu pelvic limbs. Abbreviations for muscles are in Table 1. Dashed lines indicate the expected isometric scaling exponent for each parameter. Data are for A) proximal limb muscles and B) distal limb muscles. 

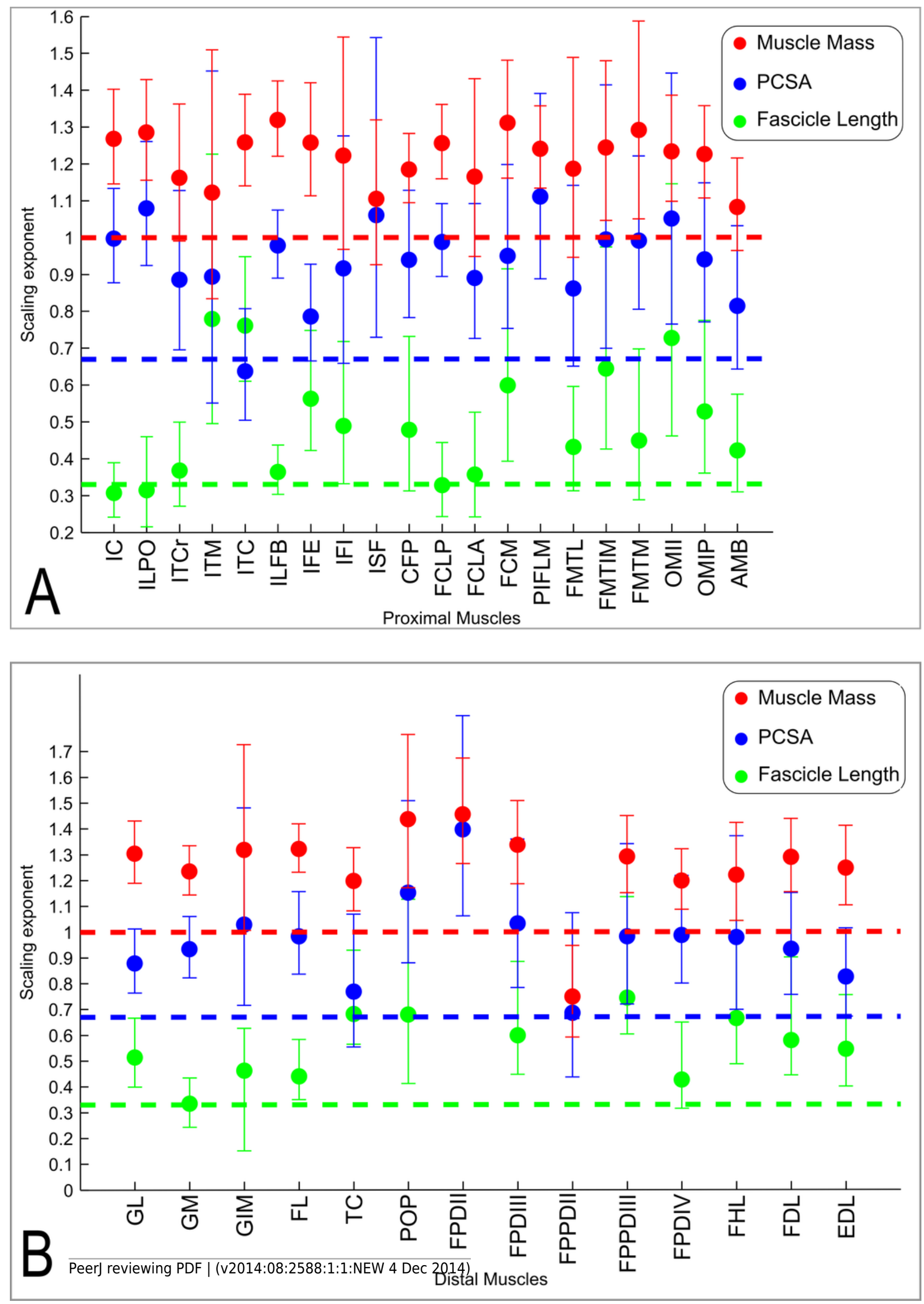


\section{6}

Ontogenetic scaling exponents, USA group.

Ontogenetic scaling exponents and 95\% confidence intervals for masses of individual muscles in emu pelvic limbs, from the USA group. Abbreviations for muscles are in Table 1. Dashed line indicates the expected isometric scaling exponent (1.0), and the number above each parameter indicates the number of muscles included in each regression analysis.

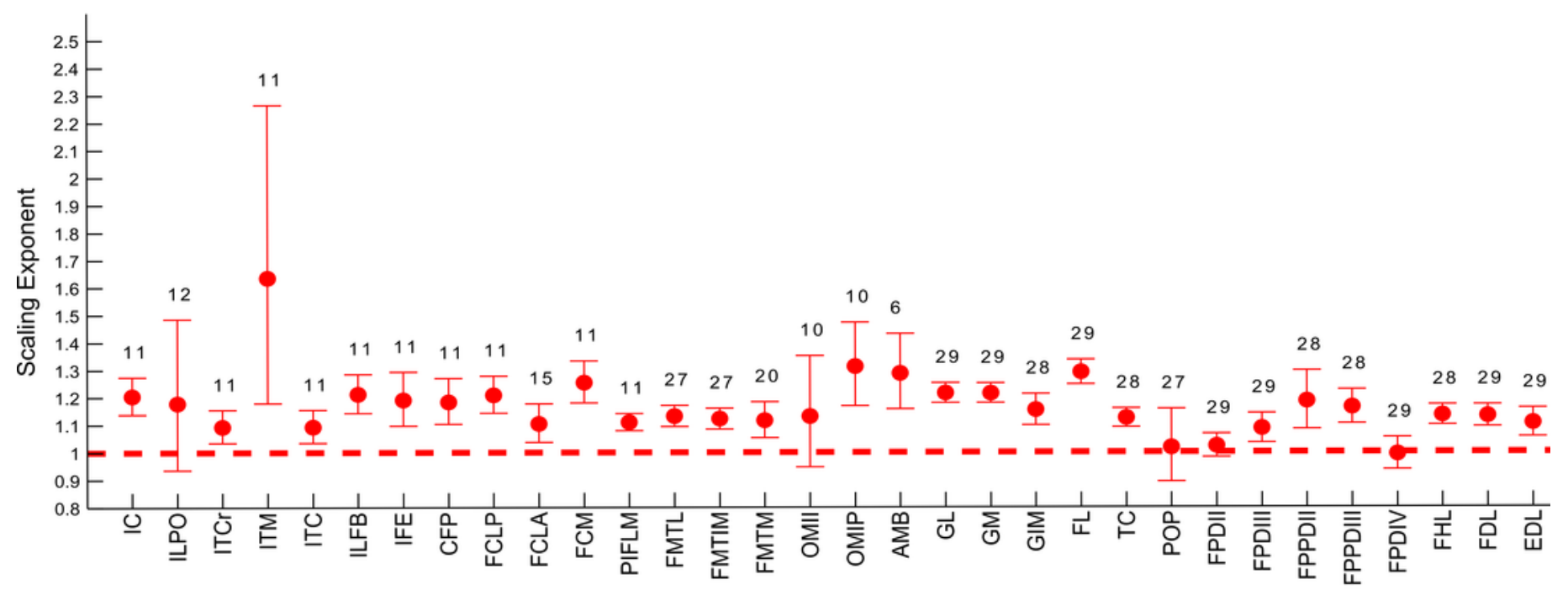


7

Ontogenetic scaling exponents of tendon properties.

Ontogenetic scaling exponents and 95\% confidence intervals for tendon mass (red), average cross-sectional area (blue) and length (green) for 20 individual muscles in emu pelvic limbs. Abbreviations for muscles are in Table 1. Dashed lines indicate the expected isometric scaling exponent for each parameter.

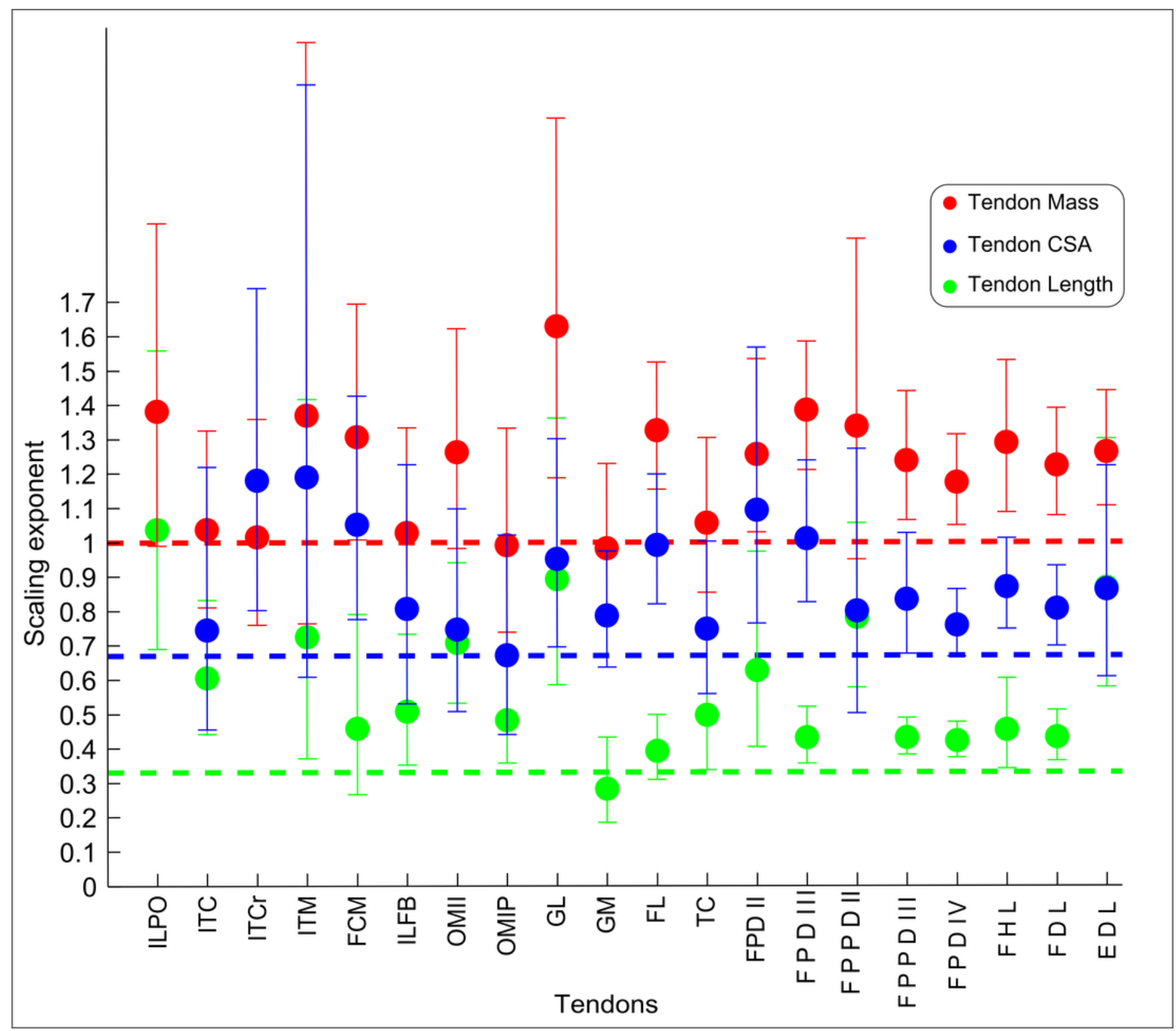




\section{Table $\mathbf{1}$ (on next page)}

Pelvic limb muscles and their apparent actions

Pelvic limb muscles of emus and their apparent actions. 


\section{Tables and table captions}

2Table 1. Pelvic limb muscles of emus and their apparent actions.

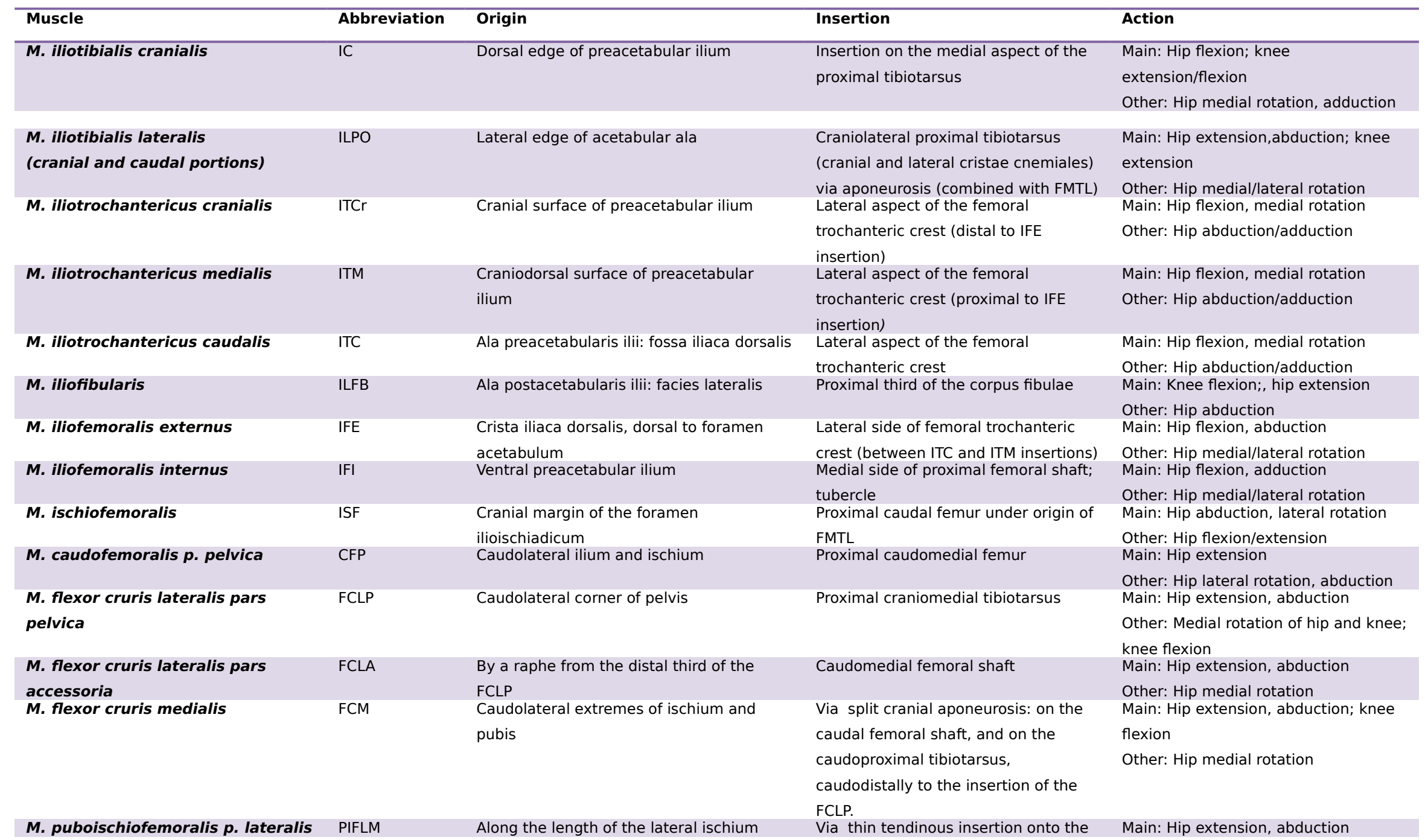




\begin{tabular}{|c|c|c|c|c|}
\hline and $p$. medialis & & & caudal aspect of the femoral shaft & Other: Hip lateral rotation \\
\hline M. femorotibialis lateralis & FMTL & Caudolateral surface of femoral shaft. With & Crista cnemalis of tibiotarsus via a & Knee extension \\
\hline (Cranial, intermediate and caudal & & 3 fused parts: cranial, intermediate and & thick patellar tendon (no ossified & \\
\hline $\begin{array}{l}\text { portions) } \\
\text { M. femorotibialis intermedialis }\end{array}$ & FMTIM & $\begin{array}{l}\text { caudal } \\
\text { Cranial surface of the proximal femoral }\end{array}$ & $\begin{array}{l}\text { patella) with ILPO } \\
\text { Medial side of crista cnemalis cranialis }\end{array}$ & Knee extension \\
\hline M. femorotibialis medialis & FMTM & $\begin{array}{l}\text { Shaft } \\
3 \text { distinct heads originating from the } \\
\text { medial surface of the femur, cranial and } \\
\text { caudal portions on the proximal third and } \\
\text { distal portion on the distal third }\end{array}$ & $\begin{array}{l}\text { of tibiotarsus } \\
\text { Proximo-medial extremity of } \\
\text { tibiotarsus }\end{array}$ & Knee flexion, adduction \\
\hline $\begin{array}{l}\text { M. obturatorius medialis (Ilium - } \\
\text { Ischium part) }\end{array}$ & OMII & Surface of fenestra ilioischium & $\begin{array}{l}\text { Long tendon that passes through the } \\
\text { foramen ilioischiadicum and inserts } \\
\text { onto the lateral side of the femoral } \\
\text { trochanteric crest }\end{array}$ & $\begin{array}{l}\text { Main: Hip lateral rotation } \\
\text { Other: Hip flexion, adduction }\end{array}$ \\
\hline $\begin{array}{l}\text { M. obturatorius medialis (Ischium } \\
\text { - pubis part) }\end{array}$ & OMIP & Surface of fenestra ischiopubica & As OMII & $\begin{array}{l}\text { Main: Hip lateral rotation } \\
\text { Other: Hip flexion, adduction }\end{array}$ \\
\hline M. ambiens & AMB & Cranial pubic rim (preacetabular process) & $\begin{array}{l}\text { Two insertions on the medial knee } \\
\text { ligaments, one tendinous and the } \\
\text { other one fleshy }\end{array}$ & $\begin{array}{l}\text { Main: Hip adduction; knee flexion } \\
\text { Other: Hip medial rotation }\end{array}$ \\
\hline M. gastrocnemius lateralis & GL & $\begin{array}{l}\text { Lateral condyle of femur, aponeurosis of } \\
\text { M. Iliotibialis and tendon from cranial } \\
\text { fibula }\end{array}$ & $\begin{array}{l}\text { Tendons fusing to form a thick fibrous } \\
\text { calcaneal pad, onto caudal side of } \\
\text { tarsometatarsus (Calcaneal scutum) }\end{array}$ & Main: Ankle extension; knee flexion \\
\hline M. gastrocnemius medialis & GM & $\begin{array}{l}\text { Aponeurosis of M. lliotibialis and facies } \\
\text { gastrocnemialis, connecting to the medial } \\
\text { surface of the proximal tibia }\end{array}$ & As GL & Main: Ankle extension; knee flexion \\
\hline M. gastrocnemius Intermedius & GIM & $\begin{array}{l}\text { Craniolateral femur, adjacent of the origin } \\
\text { of FHL muscle }\end{array}$ & As GL and GIM & Main: Ankle extension; knee flexion \\
\hline M. fibularis longus & $\mathrm{FL}$ & $\begin{array}{l}\text { Proximal origin from medial distal patellar } \\
\text { ligament and craniolaterally onto proximal } \\
\text { tibiotarsus. }\end{array}$ & $\begin{array}{l}\text { Two tendinous insertions: Plantar } \\
\text { calcaneal scutum and joining the } \\
\text { tendon of FPDIII }\end{array}$ & $\begin{array}{l}\text { Main: Ankle extension } \\
\text { Other: Knee flexion; toe flexion via } \\
\text { FPDIII tendon }\end{array}$ \\
\hline $\begin{array}{l}\text { M. tibialis cranialis c. tibiale and } \\
\text { c. femorale }\end{array}$ & TC & $\begin{array}{l}2 \text { heads: A fleshy one onto the proximal } \\
\text { cranial tibiotarsus, and via a thick tendon } \\
\text { onto the cranial aspect of the lateral } \\
\text { trochlear ridge of the femur }\end{array}$ & $\begin{array}{l}\text { Cranial side of proximal } \\
\text { tarsometatarsus }\end{array}$ & $\begin{array}{l}\text { Main: Ankle flexion } \\
\text { Other: Knee extension (femoral head) }\end{array}$ \\
\hline $\begin{array}{l}\text { M. popliteus } \\
\text { M. flexor perforatus digiti II }\end{array}$ & $\begin{array}{l}\text { POP } \\
\text { FPDII }\end{array}$ & $\begin{array}{l}\text { Medial side of proximal fibula } \\
\text { Via origin of FPDIII }\end{array}$ & $\begin{array}{l}\text { Caudal side of proximal tibiotarsus } \\
\text { Splits into } 2 \text { branches at level of }\end{array}$ & $\begin{array}{l}\text { Main: Fibular rotation } \\
\text { Main: Digit II flexion }\end{array}$ \\
\hline & & & $\begin{array}{l}\text { proximal phalanx to insert on either } \\
\text { side of middle phalanx, ventrally }\end{array}$ & Other: Ankle extension \\
\hline M. flexor perforatus digiti III & FPDIII & $\begin{array}{l}2 \text { tendons: Cranial fibula and medial side } \\
\text { of the medial condyle of the femur }\end{array}$ & $\begin{array}{l}\text { Proximal phalanx, small portion fused } \\
\text { to FPPDII tendon in some specimens, } \\
\text { ventrally }\end{array}$ & $\begin{array}{l}\text { Main: Digit III flexion } \\
\text { Other: Ankle extension }\end{array}$ \\
\hline M. flexor perforans et perforatus & FPPDII & Deep fibular tendon of $\mathrm{GL}$ muscle & Middle phalanx of digit II, ventrally & Main: Digit II flexion \\
\hline
\end{tabular}




\begin{tabular}{|c|c|c|c|c|}
\hline digiti II & FPPDII & & & Other: Ankle extension \\
\hline $\begin{array}{l}\text { M. flexor perforans et perforatus } \\
\text { digiti III }\end{array}$ & FPPDIII & Lateral knee ligaments and FPDIV origin & Middle phalanx of digit III, ventrally & $\begin{array}{l}\text { Main: Digit III flexion } \\
\text { Other: Ankle extension }\end{array}$ \\
\hline M. flexor perforatus digiti IV & FPDIV & Superficial side of FPDIII origin & Proximal and middle phalanges of & Main: Digit IV flexion \\
\hline M. flexor hallucis longus & FHL & $\begin{array}{l}2 \text { heads: lateral and caudal aspects of } \\
\text { distal femur near condyles }\end{array}$ & $\begin{array}{l}\text { digit IV, ventrally } \\
\text { Fuses with FDL tendon }\end{array}$ & $\begin{array}{l}\text { Other: Ankle extension } \\
\text { Main: Ankle extension; knee flexion }\end{array}$ \\
\hline M. flexor digitorum longus & FDL & $\begin{array}{l}2 \text { heads: proximal tibiotarsus and distal } \\
\text { third of fibula ( } 3 / 4 \text { of length) }\end{array}$ & $\begin{array}{l}\text { Splits into } 3 \text { parts above MTP joint to } \\
\text { insert onto the distal, ventral phalanx } \\
\text { of each toe }\end{array}$ & $\begin{array}{l}\text { Main: Digits II, III and IV flexion } \\
\text { Other: Ankle extension }\end{array}$ \\
\hline M. extensor digitorum longus & EDL & Cranial proximal tibiotarsus & Dorsal surface of each phalanx & $\begin{array}{l}\text { Main: Digits II, III and IV extension; } \\
\text { ankle flexion }\end{array}$ \\
\hline
\end{tabular}

3 


\section{Table 2 (on next page)}

Regression analysis results for the lengths of the four limb bones

Regression analysis results for the lengths of the four limb bones. The lower $95 \%$ boundary $(>0.33)$ demonstrates positive allometry of the tibiotarsus and the tarsometatarsus but results are closer to isometry for the femur and first phalanx of digit III. 
PeerJ Reviewing Manuscript

\begin{tabular}{|l|c|c|c|c|}
\hline Bone & $\begin{array}{l}\text { Scaling } \\
\text { exponent }\end{array}$ & $\begin{array}{l}\text { Lower 95\% } \\
\text { Cl }\end{array}$ & $\begin{array}{l}\text { Upper 95\% } \\
\text { Cl }\end{array}$ & $\mathbf{R}^{\mathbf{2}}$ \\
\hline Femur & 0.38 & 0.34 & 0.42 & 0.9 \\
\hline Tibiotarsus & 0.41 & 0.38 & 0.45 & 0.9 \\
\hline Tarsometatarsus & 0.44 & 0.39 & 0.49 & $\begin{array}{c}7 \\
6\end{array}$ \\
\hline First Phalanx (Dig III) & 0.39 & 0.33 & 0.46 & 0.9 \\
\hline
\end{tabular}

Table 2. Regression analysis results for the lengths of the four limb bones. The lower $95 \%$ boundary $(>0.33)$ demonstrates positive allometry of the tibiotarsus and the tarsometatarsus but results are closer to isometry for the femur and first phalanx of digit III. 


\section{Table 3(on next page)}

Results of RMA linear regression of muscle architecture vs. body mass (BM)

Results of RMA linear regression of muscle architecture vs. body mass (BM) for the pelvic limb of Dromaius novaehollandiae, across ontogeny. $M_{m}$, muscle mass $(\mathrm{kg}) ; L_{f}$, fascicle length $(\mathrm{m}), P C S A$, physiological cross-sectional area $\left(\mathrm{m}^{2}\right)$. 
PeerJ Reviewing Manuscript

\begin{tabular}{|c|c|c|c|c|c|c|c|c|c|c|c|c|c|c|c|}
\hline \multicolumn{6}{|c|}{$M_{m}$ vs $B M$} & \multicolumn{5}{|c|}{$L_{f} v S B M$} & \multicolumn{5}{|c|}{ PCSA vS BM } \\
\hline $\begin{array}{c}\text { Muscl } \\
e\end{array}$ & $\begin{array}{c}\text { Outlie } \\
\text { rs }\end{array}$ & Slope & $\begin{array}{c}\text { Lower } \\
95 \% \\
\mathrm{Cl}\end{array}$ & $\begin{array}{c}\text { Upper } \\
95 \% \\
\text { Cl }\end{array}$ & $R^{2}$ & $\begin{array}{c}\text { Outlie } \\
\text { rs }\end{array}$ & Slope & $\begin{array}{c}\text { Lower } \\
95 \% \\
\mathrm{Cl}\end{array}$ & $\begin{array}{c}\text { Upper } \\
95 \% \\
\mathrm{Cl}\end{array}$ & $R^{2}$ & $\begin{array}{c}\text { Outlie } \\
\text { rs }\end{array}$ & Slope & $\begin{array}{c}\text { Lower } \\
95 \% \\
\mathrm{Cl}\end{array}$ & $\begin{array}{c}\text { Upper } \\
95 \% \\
\mathrm{Cl}\end{array}$ & $R^{2}$ \\
\hline AMB & 0 & 1.08 & 0.96 & 1.21 & 0.96 & 0 & 0.42 & 0.31 & 0.57 & 0.67 & 0 & 0.81 & 0.64 & 1.03 & 0.81 \\
\hline CFP & 0 & 1.18 & 1.09 & 1.28 & 0.98 & 0 & 0.48 & 0.31 & 0.73 & 0.36 & 0 & 0.94 & 0.78 & 1.13 & 0.89 \\
\hline$E D L$ & 0 & 1.25 & 1.10 & 1.41 & 0.95 & 0 & 0.54 & 0.39 & 0.75 & 0.64 & 0 & 0.82 & 0.67 & 1.01 & 0.86 \\
\hline FCLA & 1 & 1.16 & 0.95 & 1.43 & 0.87 & 1 & 0.36 & 0.24 & 0.53 & 0.51 & 1 & 0.89 & 0.73 & 1.09 & 0.87 \\
\hline FCLP & 0 & 1.26 & 1.16 & 1.36 & 0.98 & 0 & 0.33 & 0.24 & 0.44 & 0.69 & 0 & 0.99 & 0.89 & 1.09 & 0.97 \\
\hline FCM & 1 & 1.31 & 1.16 & 1.48 & 0.95 & 1 & 0.60 & 0.39 & 0.91 & 0.42 & 1 & 0.95 & 0.75 & 1.20 & 0.83 \\
\hline$F D L$ & 1 & 1.29 & 1.15 & 1.44 & 0.96 & 1 & 0.58 & 0.37 & 0.90 & 0.36 & 1 & 0.93 & 0.76 & 1.15 & 0.86 \\
\hline FHL & 1 & 1.22 & 1.04 & 1.42 & 0.93 & 1 & 0.66 & 0.42 & 1.04 & 0.34 & 1 & 0.98 & 0.70 & 1.37 & 0.64 \\
\hline$F \boldsymbol{L}$ & 0 & 1.32 & 1.23 & 1.42 & 0.98 & 0 & 0.44 & 0.33 & 0.58 & 0.73 & 0 & 0.98 & 0.84 & 1.16 & 0.91 \\
\hline $\begin{array}{c}F M T I \\
M\end{array}$ & 0 & 1.24 & 1.05 & 1.48 & 0.90 & 0 & 0.64 & 0.43 & 0.97 & 0.40 & 0 & 0.99 & 0.70 & 1.41 & 0.57 \\
\hline FMTL & 0 & 1.19 & 0.95 & 1.49 & 0.83 & 0 & 0.43 & 0.31 & 0.60 & 0.64 & 0 & 0.86 & 0.65 & 1.14 & 0.73 \\
\hline $\begin{array}{c}F M T \\
M\end{array}$ & 0 & 1.29 & 1.05 & 1.59 & 0.86 & 0 & 0.45 & 0.29 & 0.70 & 0.31 & 0 & 0.99 & 0.80 & 1.22 & 0.85 \\
\hline FPDII & 0 & 1.45 & 1.26 & 1.67 & 0.93 & & - & - & - & - & 0 & 1.40 & 1.06 & 1.84 & 0.74 \\
\hline $\begin{array}{c}\text { FPDII } \\
\text { I }\end{array}$ & 0 & 1.34 & 1.19 & 1.51 & 0.95 & 0 & 0.60 & 0.41 & 0.88 & 0.47 & 0 & 1.03 & 0.78 & 1.36 & 0.74 \\
\hline $\begin{array}{c}\text { FPDI } \\
V\end{array}$ & 0 & 1.20 & 1.09 & 1.32 & 0.97 & 0 & 0.43 & 0.28 & 0.65 & 0.38 & 0 & 0.99 & 0.80 & 1.22 & 0.85 \\
\hline $\begin{array}{c}\text { FPPD } \\
\text { /I }\end{array}$ & 0 & 0.75 & 0.59 & 0.95 & 0.81 & 0 & 0.74 & 0.49 & 1.14 & 0.37 & 0 & 0.68 & 0.44 & 1.07 & 0.29 \\
\hline $\begin{array}{c}\text { FPPD } \\
\text { III }\end{array}$ & 0 & 1.29 & 1.15 & 1.45 & 0.96 & & - & - & - & - & 0 & 0.98 & 0.72 & 1.34 & 0.67 \\
\hline GIM & 0 & 1.32 & 1.01 & 1.73 & 0.75 & 0 & 0.46 & 0.34 & 0.63 & 0.69 & 0 & 1.03 & 0.72 & 1.48 & 0.54 \\
\hline GL & 0 & 1.30 & 1.19 & 1.43 & 0.97 & 0 & 0.51 & 0.40 & 0.67 & 0.77 & 0 & 0.88 & 0.76 & 1.01 & 0.93 \\
\hline GM & 0 & 1.24 & 1.14 & 1.33 & 0.98 & 0 & 0.34 & 0.26 & 0.43 & 0.77 & 0 & 0.93 & 0.82 & 1.06 & 0.95 \\
\hline IC & 0 & 1.27 & 1.15 & 1.40 & 0.97 & 0 & 0.31 & 0.24 & 0.39 & 0.81 & 0 & 1.00 & 0.88 & 1.13 & 0.95 \\
\hline IFE & 0 & 1.26 & 1.11 & 1.42 & 0.95 & 0 & 0.56 & 0.42 & 0.75 & 0.72 & 0 & 0.79 & 0.66 & 0.93 & 0.91 \\
\hline IFI & 2 & 1.22 & 0.97 & 1.54 & 0.85 & 2 & 0.49 & 0.33 & 0.72 & 0.57 & 2 & 0.92 & 0.66 & 1.28 & 0.68 \\
\hline IB & 0 & 1.32 & 1.22 & 1.42 & 0.98 & 0 & 0.36 & 0.30 & 0.44 & 0.89 & 0 & 0.98 & 0.89 & 1.07 & 0.97 \\
\hline ILPO & 0 & 1.29 & 1.16 & 1.43 & 0.96 & 0 & 0.31 & 0.21 & 0.46 & 0.50 & 0 & 1.08 & 0.92 & 1.26 & 0.92 \\
\hline ISF & 3 & 1.10 & 0.93 & 1.32 & 0.92 & - & - & - & - & -- & 3 & 1.06 & 0.73 & 1.54 & 0.63 \\
\hline ITC & 2 & 1.26 & 1.14 & 1.39 & 0.97 & 2 & 0.76 & 0.61 & 0.95 & 0.86 & 2 & 0.64 & 0.50 & 0.81 & 0.84 \\
\hline ITCr & 0 & 1.16 & 0.99 & 1.36 & 0.92 & 0 & 0.37 & 0.27 & 0.50 & 0.68 & 0 & 0.89 & 0.70 & 1.13 & 0.80 \\
\hline ITM & 2 & 1.12 & 0.83 & 1.51 & 0.75 & 2 & 0.78 & 0.49 & 1.23 & 0.39 & 2 & 0.89 & 0.55 & 1.45 & 0.29 \\
\hline OMII & 0 & 1.23 & 1.10 & 1.39 & 0.95 & 0 & 0.73 & 0.46 & 1.15 & 0.27 & 0 & 1.05 & 0.76 & 1.45 & 0.65 \\
\hline OMIP & 0 & 1.23 & 1.11 & 1.36 & 0.97 & 0 & 0.53 & 0.36 & 0.77 & 0.49 & 0 & 0.94 & 0.77 & 1.15 & 0.87 \\
\hline
\end{tabular}


PeerJ Reviewing Manuscript

\begin{tabular}{cccccccccccccccccc}
$\begin{array}{c}\text { PIFL } \\
\text { M }\end{array}$ & 0 & 1.24 & 1.13 & 1.36 & 0.97 & - & - & - & - & - & 0 & 1.11 & 0.89 & 1.39 & 0.83 \\
POP & 2 & 1.44 & 1.17 & 1.76 & 0.88 & 2 & 0.68 & 0.41 & 1.13 & 0.22 & 2 & 1.15 & 0.88 & 1.51 & 0.79 \\
TC & 0 & 1.20 & 1.08 & 1.33 & 0.97 & 0 & 0.68 & 0.50 & 0.93 & 0.67 & 0 & 0.77 & 0.55 & 1.07 & 0.63 \\
\hline
\end{tabular}

Table 3. Results of RMA linear regression of muscle architecture vs. body mass (BM) for the pelvic limb of Dromaius

novaehollandiae, across ontogeny. $M_{m}$, muscle mass $(\mathrm{kg}) ; L_{f}$, fascicle length $(\mathrm{m}), P C S A$, physiological cross-sectional area $\left(\mathrm{m}^{2}\right)$. 


\section{Table 4(on next page)}

Results of RMA linear regression of tendon dimensions vs. body mass (BM)

Results of RMA linear regression of tendon dimensions vs. body mass (BM) for the pelvic limb of Dromaius novaehollandiae, across ontogeny. $M_{\text {ten, }}$ tendon mass $(\mathrm{kg}) ; L_{\text {ten }}$, tendon length (m); TCSA, tendon cross-sectional area $\left(\mathrm{m}^{2}\right)$ 


\begin{tabular}{|c|c|c|c|c|c|c|c|c|c|c|c|c|c|c|c|}
\hline \multicolumn{6}{|c|}{$M_{t e n}$ vs $B M$} & \multicolumn{5}{|c|}{$L_{t e n}$ VS BM } & \multicolumn{5}{|c|}{ TCSA vs BM } \\
\hline $\begin{array}{c}\text { Tendo } \\
n\end{array}$ & $\begin{array}{c}\text { Outlier } \\
s\end{array}$ & Slope & $\begin{array}{c}\text { Lower } \\
95 \% \\
\mathrm{Cl}\end{array}$ & $\begin{array}{c}\text { Upper } \\
95 \% \\
\mathrm{Cl}\end{array}$ & $R^{2}$ & $\begin{array}{c}\text { Outlier } \\
s\end{array}$ & Slope & $\begin{array}{c}\text { Lower } \\
95 \% \\
\mathrm{Cl}\end{array}$ & $\begin{array}{c}\text { Upper } \\
95 \% \\
\mathrm{Cl}\end{array}$ & $R^{2}$ & $\begin{array}{c}\text { Outlier } \\
s\end{array}$ & Slope & $\begin{array}{c}\text { Lower } \\
95 \% \\
\mathrm{Cl}\end{array}$ & $\begin{array}{c}\text { Upper } \\
95 \% \\
\text { Cl }\end{array}$ & $R^{2}$ \\
\hline$E D L$ & 0 & 1.26 & 1.10 & 1.44 & 0.94 & 1 & -0.81 & -1.07 & -0.61 & 0.75 & 0 & 0.86 & 0.61 & 1.22 & 0.58 \\
\hline FCM & 0 & 1.31 & 1.01 & 1.69 & 0.86 & 0 & 0.46 & 0.27 & 0.79 & 0.34 & 0 & 1.05 & 0.78 & 1.43 & 0.81 \\
\hline FDL & 1 & 1.22 & 1.08 & 1.39 & 0.95 & 1 & 0.43 & 0.36 & 0.51 & 0.91 & 1 & 0.81 & 0.70 & 0.93 & 0.94 \\
\hline FHL & 1 & 1.29 & 1.09 & 1.53 & 0.91 & 1 & 0.45 & 0.34 & 0.60 & 0.74 & 1 & 0.87 & 0.75 & 1.01 & 0.93 \\
\hline $\boldsymbol{F L}$ & 0 & 1.33 & 1.15 & 1.52 & 0.94 & 0 & 0.39 & 0.31 & 0.50 & 0.81 & 0 & 0.99 & 0.82 & 1.20 & 0.88 \\
\hline FPDII & 0 & 1.26 & 1.03 & 1.53 & 0.87 & 0 & 0.63 & 0.40 & 0.97 & 0.32 & 0 & 1.09 & 0.76 & 1.57 & 0.56 \\
\hline FPDIII & 0 & 1.38 & 1.21 & 1.58 & 0.94 & 0 & 0.43 & 0.36 & 0.52 & 0.88 & 0 & 1.01 & 0.82 & 1.24 & 0.86 \\
\hline FPDIV & 0 & 1.17 & 1.05 & 1.31 & 0.96 & 0 & 0.42 & 0.37 & 0.48 & 0.95 & 0 & 0.76 & 0.67 & 0.86 & 0.95 \\
\hline $\begin{array}{c}\text { FPPDI } \\
\text { I }\end{array}$ & 0 & 1.34 & 0.95 & 1.88 & 0.60 & 0 & 0.78 & 0.58 & 1.06 & 0.69 & 0 & 0.80 & 0.50 & 1.27 & 0.24 \\
\hline $\begin{array}{c}\text { FPPDI } \\
\text { /I }\end{array}$ & 0 & 1.24 & 1.06 & 1.44 & 0.92 & 0 & 0.43 & 0.38 & 0.49 & 0.95 & 0 & 0.83 & 0.68 & 1.03 & 0.85 \\
\hline GL & 0 & 1.63 & 1.19 & 2.23 & 0.66 & 0 & 0.89 & 0.59 & 1.36 & 0.38 & 0 & 0.95 & 0.69 & 1.30 & 0.66 \\
\hline GM & 0 & 0.98 & 0.78 & 1.23 & 0.83 & 0 & 0.28 & 0.18 & 0.43 & 0.37 & 0 & 0.79 & 0.64 & 0.97 & 0.85 \\
\hline IB & 1 & 1.03 & 0.79 & 1.33 & 0.79 & 1 & 0.51 & 0.35 & 0.73 & 0.57 & 1 & 0.81 & 0.53 & 1.23 & 0.43 \\
\hline ILPO & 2 & 1.38 & 0.99 & 1.93 & 0.68 & 2 & 1.04 & 0.69 & 1.56 & 0.51 & - & - & - & - & - \\
\hline ITC & 3 & 1.04 & 0.81 & 1.33 & 0.84 & 3 & 0.61 & 0.44 & 0.83 & 0.74 & 3 & 0.75 & 0.46 & 1.22 & 0.34 \\
\hline ITCr & 1 & 1.02 & 0.76 & 1.36 & 0.73 & - & - & - & - & - & 1 & 1.18 & 0.80 & 1.74 & 0.52 \\
\hline ITM & 7 & 1.37 & 0.76 & 2.46 & 0.43 & 6 & 0.72 & 0.37 & 1.42 & 0.09 & 7 & 1.19 & 0.61 & 2.33 & 0.21 \\
\hline OMII & 0 & 1.26 & 0.98 & 1.62 & 0.79 & 0 & 0.71 & 0.53 & 0.94 & 0.72 & 0 & 0.75 & 0.51 & 1.10 & 0.48 \\
\hline OMIP & 0 & 0.99 & 0.74 & 1.33 & 0.70 & 1 & 0.48 & 0.36 & 0.65 & 0.71 & 1 & 0.67 & 0.44 & 1.02 & 0.43 \\
\hline$T C$ & 0 & 1.06 & 0.85 & 1.30 & 0.85 & 0 & 0.50 & 0.34 & 0.73 & 0.47 & 0 & 0.75 & 0.56 & 1.00 & 0.71 \\
\hline
\end{tabular}

Table 4. Results of RMA linear regression of tendon dimensions vs. body mass (BM) for the pelvic limb of Dromaius

novaehollandiae, across ontogeny. $M_{\text {ten }}$, tendon mass $(\mathrm{kg}) ; L_{\text {ten }}$, tendon length $(\mathrm{m})$; $T C S A$, tendon cross-sectional area $\left(\mathrm{m}^{2}\right)$. 